\title{
Polysome profiling reveals translational control of gene expression in the human malaria parasite Plasmodium falciparum
}

\author{
Evelien M Bunnik', Duk-Won Doug Chung ${ }^{1}$, Michael Hamilton ${ }^{1}$, Nadia Ponts ${ }^{1,2}$, Anita Saraf ${ }^{3}$, Jacques Prudhomme ${ }^{1}$, \\ Laurence Florens ${ }^{3}$ and Karine G Le Roch ${ }^{1,4^{*}}$
}

\begin{abstract}
Background: In eukaryotic organisms, gene expression is regulated at multiple levels during the processes of transcription and translation. The absence of a tight regulatory network for transcription in the human malaria parasite suggests that gene expression may largely be controlled at post-transcriptional and translational levels.

Results: In this study, we compare steady-state mRNA and polysome-associated mRNA levels of Plasmodium falciparum at different time points during its asexual cell cycle. For more than $30 \%$ of its genes, we observe a delay in peak transcript abundance in the polysomal fraction as compared to the steady-state mRNA fraction, suggestive of strong translational control. Our data show that key regulatory mechanisms could include inhibitory activity of upstream open reading frames and translational repression of the major virulence gene family by intronic transcripts. In addition, we observe polysomal mRNA-specific alternative splicing events and widespread transcription of non-coding transcripts.

Conclusions: These different layers of translational regulation are likely to contribute to a complex network that controls gene expression in this eukaryotic pathogen. Disrupting the mechanisms involved in such translational control could provide novel anti-malarial strategies.
\end{abstract}

\section{Background}

Malaria is still one of the most deadly infectious diseases worldwide, claiming an estimated 660,000 lives per year [1]. The vast majority of deaths occur among children under the age of 5 years living in sub-Saharan Africa [1]. Over the past decade, malaria control measures have reduced the global incidence and mortality rates by $17 \%$ and $26 \%$, respectively [1]. However, the absence of a preventive vaccine and the spread of drug-resistant parasite strains warrant continued investigations into the intricate biology of the malaria parasite, in search of novel anti-malarial drug targets.

The malaria parasite species Plasmodium falciparum is responsible for $90 \%$ of all malaria deaths [1]. The complex life cycle of $P$. falciparum involves multiple

\footnotetext{
* Correspondence: karine.leroch@ucr.edu

${ }^{1}$ Department of Cell Biology and Neuroscience, University of California Riverside, 900 University Ave, Riverside, CA 92521, USA

${ }^{4}$ Institute for Integrative Genome Biology, Center for Disease Vector Research, Department of Cell Biology and Neuroscience, University of California

Riverside, 900 University Avenue, Riverside, CA 92521, USA

Full list of author information is available at the end of the article
}

stages in both the human and the mosquito host. The symptomatic phase of $P$. falciparum infection is the erythrocytic stage, where the parasite replicates in red blood cells and progresses through the ring, trophozoite and schizont stages to produce 16 to 32 daughter cells. The release of these daughter cells, or merozoites, into the blood stream after the completion of each 48-hour cycle of cell division causes the typical pattern of recurring fevers. Environmental stress, such as low nutrient levels, induces the formation of gametocytes, the sexual forms of $P$. falciparum, which can be transferred to a mosquito host when it takes a blood meal.

The multiplication process during the erythrocytic cell cycle of $P$. falciparum infection is tightly regulated and involves the expression of the majority of its genes [2-4]. However, the regulation of gene expression in P. falciparum is still incompletely understood. Relatively few transcription factors have been identified $[5,6]$, while changes in chromatin structure seem to play a unique role in transcriptional control $[7,8]$. Moreover, for a large proportion of genes 
expressed in the erythrocytic cycle, transcriptional activity does not correlate well with protein abundance $[9,10]$, similar to mammalian cells where the initiation of translation, and not transcript abundance, is the main determinant of protein levels [11]. In Plasmodium berghei gametocytes, delayed translation of two transcripts was shown to occur by temporary storage of these transcripts in P-bodies, followed by transfer to ribosomes after ingestion of gametocytes by a mosquito [12]. RNA-binding proteins are likely to be involved in translational repression at this stage [13]. In addition, latency of $P$. berghei sporozoites is controlled by phosphorylation of eukaryotic initiation factor- $2 \alpha$, resulting in inhibition of translation [14]. However, the mechanisms and the extent of post-transcriptional and translational control have not yet been described for the asexual stage of $P$. falciparum.

In other eukaryotic organisms, a multitude of mechanisms act in concert to regulate gene expression at a posttranscriptional level, including mRNA splicing, decay, binding of inhibitory proteins and the actions of regulatory mRNA elements. One of the major regulatory mechanisms of mRNA abundance in higher eukaryotes is RNA interference, but homologues of the RNA interference machinery have not been identified in the P. falciparum genome [15].

In this study, we performed next-generation sequencing of both steady-state mRNA and polysome-associated mRNA, presumed to be actively translated. Our genomewide approach allowed us to elucidate the extent of translational control during the erythrocytic cell cycle of $P$. falciparum and to identify key mechanisms likely contributing to the complex regulatory network of gene expression and parasite virulence. Collectively, our results increase our understanding of parasite development throughout the infectious cell cycle, which may contribute to novel antimalarial strategies.

\section{Results}

Generation of steady-state mRNA and polysomal mRNA datasets across the $P$. falciparum asexual cycle

To investigate differences between transcription and translation during the erythrocytic cycle of $P$. falciparum strain 3D7, we isolated both steady-state mRNA and polysome-associated mRNA at different stages throughout the parasite's cell cycle. Parasites were harvested directly after the invasion of the red blood cell at the early ring stage $(0 \mathrm{~h})$, as well as at the trophozoite $(18 \mathrm{~h})$ and schizont ( $36 \mathrm{~h})$ stages. For steady-state mRNA, we first isolated total RNA from the parasites, followed by mRNA purification using poly-A selection. Based on the amounts of mRNA isolated per flask of parasites, high abundance of transcripts was observed during the trophozoite and schizont stages of the erythrocytic cycle (Table 1). For polysomal mRNA, we isolated polysomes by sucrose density gradient centrifugation [16], also followed by mRNA purification using poly-A selection. Translational activity peaked at the schizont stage (Table 1; Figure 1). Polysomes were absent in a profile from cultured uninfected erythrocytes, indicating that contamination levels of human ribosomes in polysome isolations from $P$. falciparum cultures were very low (Figure 1D). In addition, to validate the selectivity of our polysome isolation procedure, we analyzed polysome fractions by highly sensitive, semi-quantitative massspectrometry (multidimensional protein identification technology; MudPIT [17]). Our analysis yielded 95.6\% ribosomal proteins, $2.0 \%$ RNA-binding and ribosomeassociated proteins (such as translation initiation factors, elongation factors, and other RNA-binding proteins), $0.5 \%$ proteins with unknown functions and $2.0 \%$ contaminants (Table S1 in Additional file 1), indicative of a high purity of our polysome fractions. Both steady-state and polysomal mRNA fractions were treated with DNase to remove genomic DNA contamination. Even though steady-state mRNA contains all of the polysomeassociated mRNA, the polysomal fraction is presumed to be highly enriched for actively translated mRNA and is thus considered a different mRNA population. Using next-generation sequencing (Illumine HiSeq 2000), we obtained an average of 7.1 and 3.0 million high quality reads per stage for the steady-state mRNA and polysomal mRNA datasets, respectively, corresponding to an average of 21.5X and 6.6X exome-wide coverage (Table 1). We

Table 1 Number of working reads and normalization factor for each library

\begin{tabular}{|c|c|c|c|c|c|}
\hline mRNA fraction & $\begin{array}{c}\text { Time point } \\
\text { (hours post-invasion) }\end{array}$ & $\begin{array}{l}\text { mRNA quantity per } \\
10^{9} \text { parasites }(\mu \mathrm{g})\end{array}$ & $\begin{array}{c}\text { Number of } \\
\text { working reads }\end{array}$ & $\begin{array}{l}\text { Exome-wide } \\
\text { coverage }\end{array}$ & $\begin{array}{l}\text { Scaling } \\
\text { factor }\end{array}$ \\
\hline \multirow[t]{3}{*}{ Steady-state } & $\mathrm{Oh}$ & 0.56 & $7,663,318$ & $22.0 \mathrm{X}$ & 5.3 \\
\hline & $18 \mathrm{~h}$ & 1.89 & $8,786,721$ & $27.2 X$ & 1.8 \\
\hline & $36 \mathrm{~h}$ & 1.90 & $4,942,888$ & $15.4 X$ & 1.0 \\
\hline \multirow[t]{4}{*}{ Polysomal } & $\mathrm{Oh}$ & 0.07 & 438,272 & $0.69 x$ & 1.0 \\
\hline & $18 \mathrm{~h}$ & 0.24 & $5,708,551$ & $12.7 X$ & 4.0 \\
\hline & $36 \mathrm{~h}$ & 0.33 & $2,809,130$ & $6.3 x$ & 1.4 \\
\hline & $36 \mathrm{~h}$ - biological replicate & 0.32 & 846,855 & $1.9 X$ & NA \\
\hline
\end{tabular}




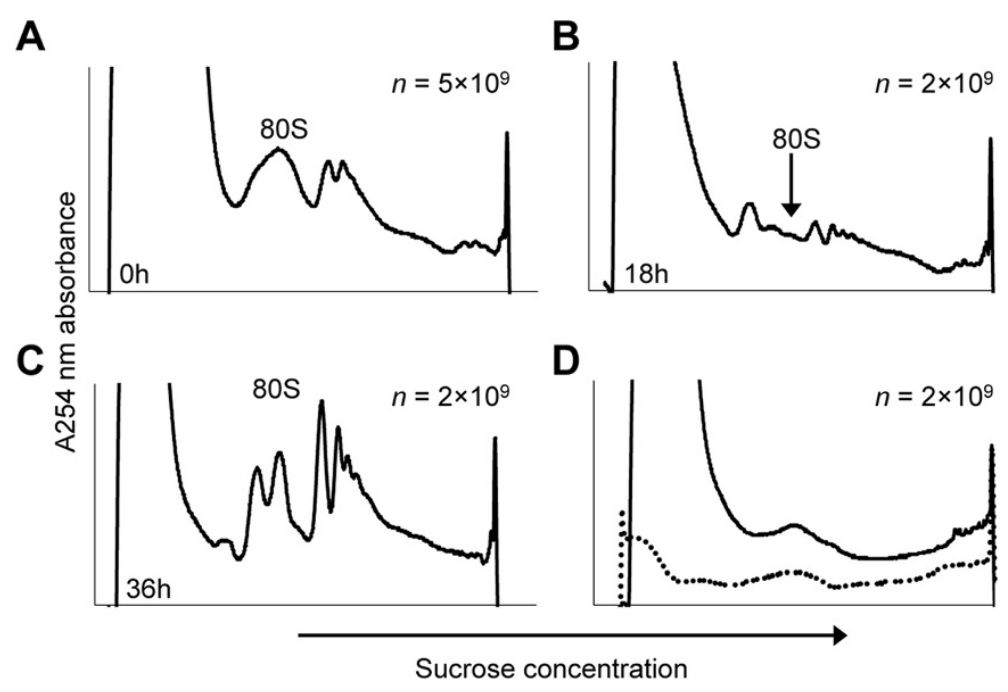

Figure 1 Polysome profiles from different time points during the erythrocytic cycle of $P$. falciparum. (A-C) Polysome sucrose (15 to 60\%) absorbance $\left(\mathrm{A}_{254} \mathrm{~nm}\right.$ ) profiles obtained from erythrocytes infected with ring-stage (A), trophozoite-stage (B), or schizont-stage (C) parasites. (D) Profiles obtained from an uninfected erythrocyte culture (black line) and a blank gradient (dotted line). The number of parasites used to obtain each profile is indicated in the top right corner of the graph. For the uninfected culture in (D), the amount of culture used was equal to the amount of infected culture containing the indicated number of parasites. The monosome peak is marked as 805 .

observed a high correlation for gene expression values of biological replicates (Pearson $\mathrm{R}=0.90$; Figure $\mathrm{S} 1 \mathrm{~A}$ in Additional file 2), confirming the reproducibility of our methodology. Genome-wide gene expression levels also correlated well between our steady-state mRNA-Seq dataset and previously published microarray $(R>0.54)$ and RNA-Seq datasets $(R>0.70) \quad[3,4,18]$ (Figure $S 1 B, C$ in Additional file 2). Considering the fact that microarray and RNA-Seq data only agree well for genes with medium expression levels [19], the correlation coefficients that we obtained for our datasets further validate our sequencing results.

To compare gene expression levels between the different stages of the asexual cycle, we normalized the total sequence read counts of each library to directly reflect the mRNA levels per parasite at that stage. This was achieved by introducing a scaling factor for the sequence read counts per gene based on the total amount of mRNA isolated per flask (see Materials and methods; Table 1). After normalization, the distribution of read counts per gene for the trophozoite and schizont time points was relatively similar, while the average expression level of genes at the ring stage was much lower (Figure S2 in Additional file 2), corresponding to relative mRNA levels per parasite for each stage.

\section{Cluster analysis of steady-state and polysomal mRNA profiles across the asexual cell cycle}

We detected a total of 4,633 expressed genes (85.0\% of all protein-coding genes) in our datasets, albeit at very low levels for some genes, which is comparable to previous expression analyses in $P$. falciparum [3,4]. Genome-wide, both steady-state mRNA levels and polysomal mRNA levels varied over five orders of magnitude, while expression levels for individual genes across the cell cycle ranged within three orders of magnitude. Median variation in expression levels between different time points of the cell cycle were 3.8-fold for steadystate mRNA and 3.6-fold for polysomal mRNA. Of the genes that were present in both the steady-state mRNA and the polysome-associated mRNA datasets, 4,007 genes $(73.5 \%)$ were cell cycle-regulated (defined as more than two-fold difference in expression levels across the cell cycle). Both the steady-state and the polysomal transcript abundance data were independently clustered based on expression profiles, resulting in five steadystate mRNA and six polysomal mRNA clusters (Figure 2). Most transcripts accumulated or were actively translated exclusively in one stage (clusters 1,2 , and 5 of the two datasets). However, for both the steady-state mRNA and polysomal mRNA datasets, we also identified a substantial number of genes with expression profiles overlapping the trophozoite and schizont stages (clusters 3 and 4). For most of these genes, expression peaked in one of the two stages with lower expression levels in the second stage. In addition, we observed a cluster of 171 genes that were associated with polysomes in both the schizont and the ring stage (cluster B.6). Gene ontology (GO) analysis showed large and coordinated shifts in the expression of groups of genes with common biological function in major cellular processes as the parasite progressed through its cell cycle (Figure 2; Tables S2 and S3 


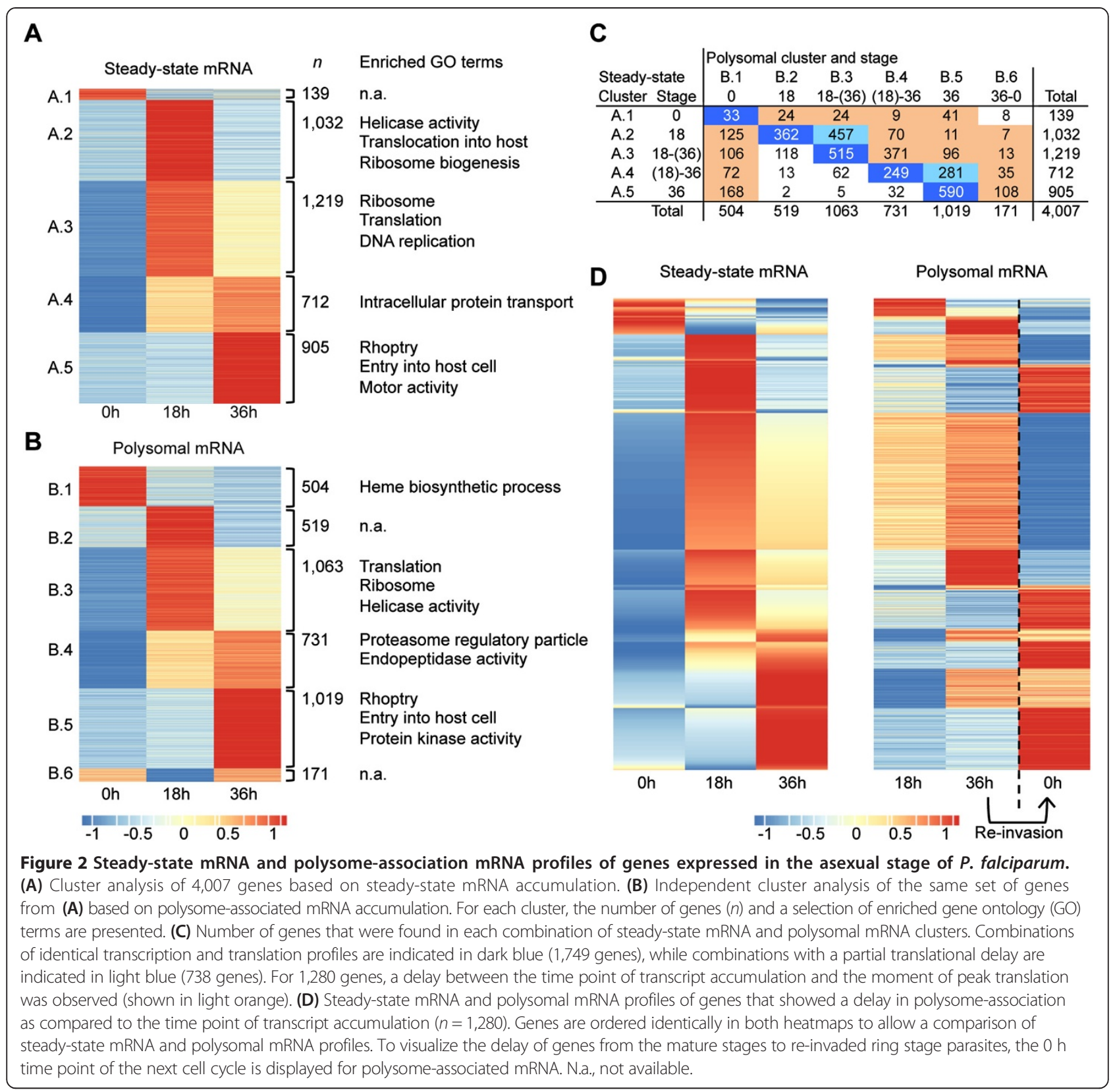

in Additional file 2). In preparation for translating the majority of its genes at the mature stages, genes involved in the process of translation, such as ribosomal proteins, were abundant and highly translated at the $18 \mathrm{~h}$ time point (clusters A.2, A.3, B.2, and B.3). A peak in transcript abundance of genes related to DNA replication was observed in the cluster peaking at the trophozoite stage but overlapping the schizont stage (cluster A.3), corresponding to the period of massive DNA replication that takes place as the parasite divides into daughter cells. Finally, transcripts for genes involved in invasion of a new host cell, such as rhoptry proteins, were highest in both the steady-state and polysome fraction from the schizont stage (clusters A.5 and B.5; Figure 2), just before merozoites are released into the blood stream to invade new red blood cells. The polysomal mRNA cluster analysis additionally showed enrichment of genes involved in heme biosynthetic process at the ring stage (cluster B.1) and of genes associated with protein degradation at the schizont stage (cluster B.4) (Figure 2B).

\section{Comparison of steady-state mRNA and polysomal mRNA profiles across the cell cycle}

A comparison of steady-state mRNA and polysomal mRNA expression clusters revealed that for 1,749 genes (43.6\%), transcription and translation showed similar 
patterns of upregulation, with transcripts peaking at the same time points in both fractions. For another 738 genes (18.4\%), we observed a partial delay in the timing of translation as compared to the moment of transcription. For example, 457 genes were highly abundant in steady-state mRNA at the trophozoite stage but absent at the schizont stage (cluster A.2), while their abundance in polysomal mRNA peaked at the trophozoite stage and continued to the schizont stage (cluster B.3). Considering the $18 \mathrm{~h}$ window between the trophozoite and schizont time points, these partial shifts between steady-state mRNA and polysomal mRNA profiles are likely to be biologically relevant. In addition, we identified 1,280 genes (31.9\%) for which translation was markedly delayed compared to the time point of transcription (Figure 2C,D). Among genes for which translation was delayed until the schizont stage, we found enrichment of genes involved in energy production (ATP synthesis-coupled proton transport; $P=1.2 \mathrm{E}-06)$.

More importantly, a substantial number of genes $(n=471)$ was found to be transcribed in the trophozoite and/or schizont stages of the cell cycle, while they were most highly associated with polysomes in the ring stage, suggesting that these transcripts are temporarily stored in the parasite and are not translated until after invasion of a new host cell. Among others, this group contained many genes involved in erythrocyte remodeling, such as members of the FIKK kinase family ( $n=2$ out of 16), the Maurer's cleft two transmembrane (MC-2TM) protein family ( $n=7$ out of $11, P=0.0027)$, Ring-infected erythrocyte surface antigen (RESA)-like proteins $(n=1$ out of 4) and genes whose products are exported to the surface of the infected red blood cell $(n=31$ out of 118 , $P<0.0001 ;$ Table 2). The first two protein families localize to the Maurer's cleft, a parasite structure in the cytoplasm of the infected erythrocyte necessary for trafficking of exported proteins to the cell surface. In addition, we observed a delay in translation for genes involved in metabolism, such as beta-ketoacyl-acyl carrier protein reductase (FabG; PF3D7_0922900) and acyl-CoA synthetase (ACS6; PF3D7_0401900). For FabG, the ratio of transcripts in steady-state versus polysome fractions was 1:47 at the ring stage, 2.6:1 at the trophozoite stage, and 3.5:1 at the schizont stage, while ACS6 showed ratios of 1:2.7, 2.2:0 and 2.2:1 at ring, trophozoite and schizont stages, respectively. Finally, based on our cluster analysis, a translational delay at any stage during the cell cycle was observed for seven out of 18 ApiAP2 transcription factors, 11 out of 11 key regulatory proteins encoded by the apicoplast, an organelle specific to apicomplexan organisms, and 565 out of 1,697 conserved Plasmodium proteins with unknown function (Table 2).

\section{Differences in mRNA landscape between steady-state mRNA and polysomal mRNA}

To identify mechanisms that may be involved in translational control, we compared genome coverage of sequence reads between our steady-state mRNA and polysomeassociated mRNA datasets throughout the parasite cell cycle. The steady-state and polysomal mRNA landscapes were strikingly different (Figure 3). For steady-state mRNA, more than $85 \%$ of sequence reads mapped to

Table 2 Number of translationally delayed genes for selected groups of parasite-specific proteins

\begin{tabular}{|c|c|c|c|c|c|c|c|c|}
\hline \multirow[b]{2}{*}{ Group } & \multirow[b]{2}{*}{ Delay $^{\mathrm{a}}(n)$} & \multirow[b]{2}{*}{$\begin{array}{c}\text { Delay to } \\
\text { R stage }^{\mathrm{b}}(n)\end{array}$} & \multicolumn{2}{|c|}{$\begin{array}{l}\text { Average normalized } \\
\text { read count per } \\
1 \mathrm{~kb} \text { exon (delay) }\end{array}$} & \multirow[b]{2}{*}{ No delay $(n)$} & \multicolumn{2}{|c|}{$\begin{array}{l}\text { Average normalized } \\
\text { read count per } 1 \mathrm{~kb} \\
\text { exon (no delay) }\end{array}$} & \multirow[b]{2}{*}{$P$-value } \\
\hline & & & $\begin{array}{c}\text { Steady-state } \\
\text { mRNA }\end{array}$ & $\begin{array}{c}\text { Polysomal } \\
\text { mRNA }\end{array}$ & & $\begin{array}{c}\text { Steady-state } \\
\text { mRNA }\end{array}$ & $\begin{array}{c}\text { Polysomal } \\
\text { mRNA }\end{array}$ & \\
\hline FIKK kinase family & 8 & 2 & 113 & 25 & 8 & 232 & 30 & - \\
\hline MC-2TM & 7 & 7 & 39 & 18 & 4 & 209 & 72 & 0.0027 \\
\hline RESA-like protein & 2 & 1 & 23 & 9 & 2 & 71 & 12 & - \\
\hline Plasmepsin & 5 & 3 & 251 & 40 & 3 & 1,913 & 113 & - \\
\hline Exported proteins & 47 & 31 & 559 & 66 & 71 & 1,234 & 258 & $<0.001$ \\
\hline ApiAP2 transcription factor & 7 & 1 & 354 & 67 & 11 & 353 & 28 & - \\
\hline Apicoplast-encoded proteins & 11 & 11 & 110 & 97 & 0 & NA & NA & $<0.001$ \\
\hline Apicoplast-targeted proteins & 120 & 50 & 420 & 90 & 255 & 969 & 283 & - \\
\hline Conserved proteins, unknown function & 565 & 237 & 340 & 89 & 1,132 & 514 & 166 & - \\
\hline Total $^{d}$ & 1,280 & 471 & 515 & 114 & 2,727 & 832 & 216 & NA \\
\hline $\begin{array}{l}\text { a Defined as at least } 18 \mathrm{~h} \text { delay in peak abur } \\
\text { b Subset of delayed genes, showing peak stea } \\
\text { 'Bonferroni-corrected two-tailed Fisher's exa } \\
\text { per group. } P \text {-values }>0.01 \text { are indicated witl } \\
\text { d Total number of expressed and cell-cycle } \\
\text { NA., not applicable. }\end{array}$ & $\begin{array}{l}\text { ndance levels } \\
\text { ady-state mRNA } \\
\text { act test for nur } \\
\text { h a dash. } \\
\text { egulated gene }\end{array}$ & $\begin{array}{l}\text { in polysomal mb } \\
\text { A abundance in } \\
\text { mber of genes } s \\
\text { es included in ou }\end{array}$ & $\begin{array}{l}\text { RNA as compared } \\
\text { he trophozoite or } \\
\text { howing translatio } \\
\text { ur analysis. }\end{array}$ & $\begin{array}{l}\text { to steady-sta } \\
\text { schizont stage } \\
\text { onal delay to th }\end{array}$ & $\begin{array}{l}\text { te mRNA. } \\
\text { and peak polyso } \\
\text { he ring stage ver }\end{array}$ & $\begin{array}{l}\text { mal mRNA abund } \\
\text { sus the number }\end{array}$ & $\begin{array}{l}\text { dance in the rin } \\
\text { of non-delayed }\end{array}$ & $\begin{array}{l}\text { g stage. } \\
\text { genes }\end{array}$ \\
\hline
\end{tabular}




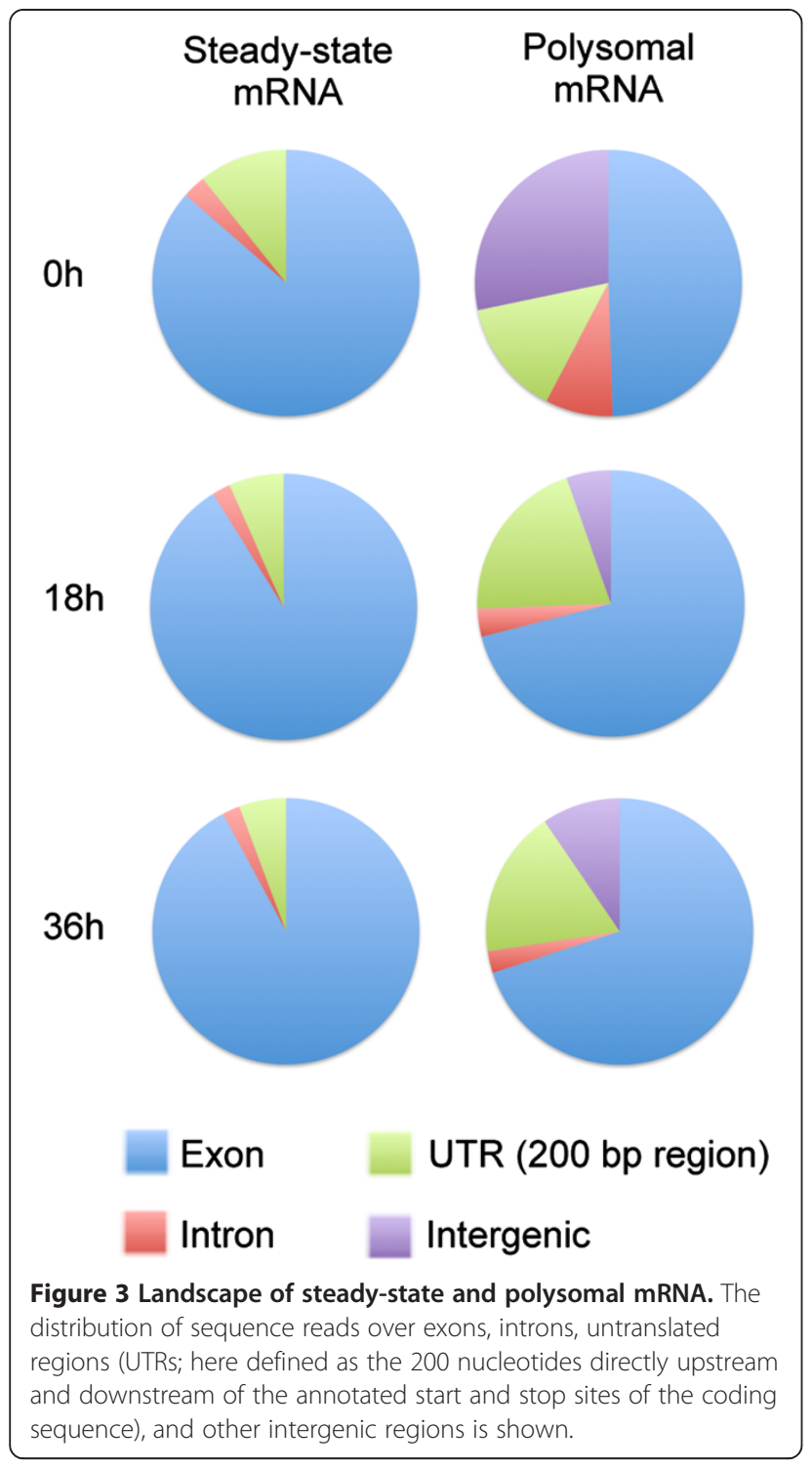

coding sequence (CDS) regions, while between 29 and 50\% of the polysomal mRNA reads mapped to introns, untranslated regions (UTRs) or other intergenic sequences. In particular, the low level of translation at the $0 \mathrm{~h}$ time point may allow us to detect non-annotated transcripts from intergenic regions present at very low levels, which could be overshadowed by highly translated genes at the later time points. To further investigate these differences, we studied the $5^{\prime}$ UTR, the $3^{\prime}$ UTR and the intronic regions in more detail, as addressed in the sections below.

\section{Control of translation by upstream open reading frames}

In the polysomal mRNA dataset, a coverage plot of the start region averaged across all genes showed an increased coverage of the $5^{\prime}$ UTR region in combination with a lower coverage in the CDS (Figure 4A). In total, 409 genes showed more than two-fold read coverage in their $5^{\prime}$ UTR as compared to their CDS (Figure 4B). For three genes, this increased 5' UTR coverage was validated by semi-quantitative RT-PCR, indicating that this phenomenon is unlikely to be the result of a bias introduced by the library preparation or sequencing reaction (Figure S3A in Additional file 2). In addition, reverse transcription using directional primers showed that mRNA covering the 5' UTR was transcribed in the sense direction (Figure S3B in Additional file 2). We further validated our data using northern blot analysis. For genes with high $5^{\prime}$ UTR coverage, northern blots showed the presence of the full-length transcript in steady-state RNA, but smaller transcript fragments in polysomal RNA (Figure 4C). The presence of these smaller transcript fragments could either indicate a specific enrichment for truncated or non-coding transcripts in polysomal RNA, protection of mRNA by ribosomes or be the result of non-specific degradation of the full-length transcript, although the latter is unlikely considering the high quality of our RNA samples (RNA Integrity Numbers (RINs) are 8.6 and 8.0 for steady state and polysomal total RNA, respectively, and $28 \mathrm{~S}$ and $18 \mathrm{~S}$ ribosomal RNA are present in a 2:1 ratio; Figure 4C).

In the 5' UTR coverage plot, we observed that coverage peaked at the start codon of polysome-associated mRNA (Figure 4A). A similar pattern was previously observed in ribosome-protected fragments from cycloheximide-treated cells [20]. In contrast, apicoplast-encoded genes that are translated in the apicoplast by $70 \mathrm{~S}$ ribosomes did not show this peak in sequence coverage at the translation start site (Figure 4A). Since 70S ribosomes are insensitive to cycloheximide inhibition [21], excess coverage at the ATG start codon in our polysome-associated mRNA dataset is likely to be the result of cycloheximide-induced ribosome stalling, indicating that even though our mRNA was not nuclease-digested, the binding sites of ribosomes, initiation factors or RNA binding proteins may be enriched in our sequencing data. If binding of ribosomes or proteins indeed influences gene coverage profiles, the high coverage in 5' UTR regions in this subset of genes may be explained by protection of this region. High 5' UTR read coverage in this subset of genes may be explained by protection of this region and may thus be the result of the presence of upstream open reading frames (uORFs) that are actively translated. It has been documented that uORFs can limit the translation of the downstream open reading frame (ORF) in a regulated manner $[22,23]$ and that re-initiation capacity of the ribosome is strongly reduced after translating an ORF of 35 or more codons [24]. In line with these data, we observed that a larger proportion of transcripts that showed a translational delay from the trophozoite to the ring stage had a high 5' UTR coverage (19.0\%) compared to transcripts that did not show a translational delay (9.7\%) (two-tailed Fisher exact test $P=0.005$; Figure 4D). Genes with high 5' UTR coverage and delayed translation 


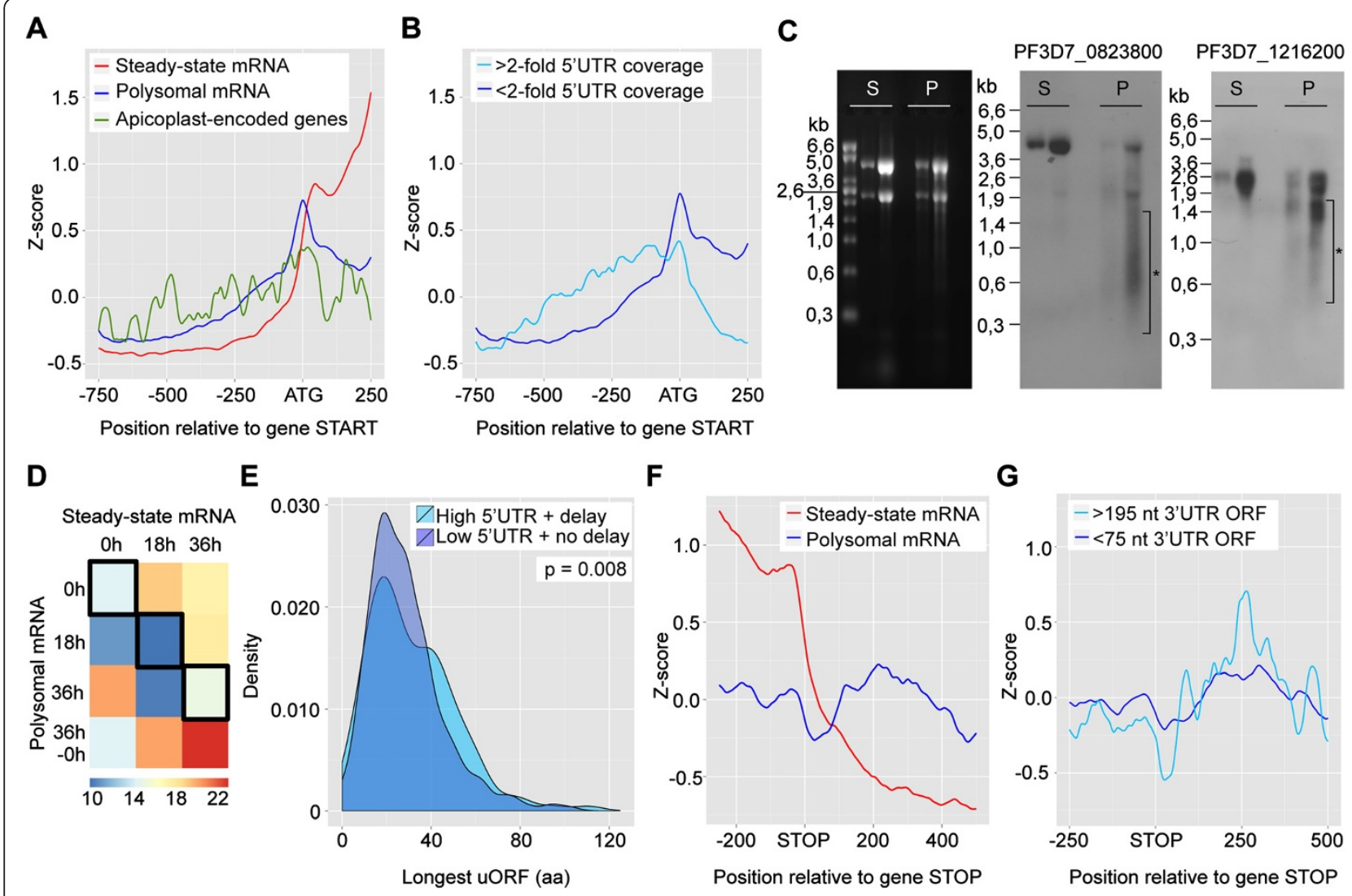

Figure 4 Increased 5' UTR and 3' UTR coverage in the polysomal mRNA. (A) Comparison of genome-wide $5^{\prime}$ UTR coverage at the $18 \mathrm{~h}$ time point between steady-state mRNA (red), polysomal mRNA (blue) and the subset of apicoplast-encoded genes in polysomal mRNA (green).

(B) Increased 5' UTR coverage in a subset of genes in polysomal mRNA. (C) Gel electrophoresis of steady-state RNA (S) and polysome-associated RNA (P) (left) from trophozoite-stage parasites, and northern blots of the same RNA fractions using a probe designed to detect sense transcripts containing the 5' UTR of gene PF3D7_0823800 (middle), or gene PF3D7_1216200 (right). Smaller transcript fragments that are observed in the polysomal fraction but not in the steady-state fraction are marked with an asterisk. (D) Heatmap showing the percentage of genes with high 5' UTR coverage out of the total number of genes for each combination of steady-state mRNA and polysomal mRNA profiles. Combinations where transcription and translation peak at the same time point are boxed. For clarity, expression profiles were grouped based on the time point of highest expression (for example, expression profiles $18 \mathrm{~h}$ and $18 \mathrm{~h}$ to (36 h) were grouped as $18 \mathrm{~h}$ ). (E) Distribution of the longest upstream open reading frame (UORF) in genes that are expressed at the $18 \mathrm{~h}$ stage and that show high $5^{\prime}$ UTR coverage and translational delay, in comparison to genes that have low $5^{\prime}$ UTR coverage and no translational delay. The difference in distribution was tested for statistical significance using the Kolmogorov-Smirnov test. (F) Comparison of genome-wide 3' UTR coverage at the $18 \mathrm{~h}$ time point between steady-state mRNA (red) and polysomal mRNA (blue). (G) Increased 3' UTR coverage in polysomal mRNA for genes with a large ORF directly downstream of the stop codon (encoding a >65 amino acid (aa) peptide) as compared to genes with short ( $<25$ amino acids) downstream ORFs, suggestive of stop codon readthrough.

also have significantly longer uORFs as compared to genes with low 5' UTR coverage and no delay in translation $(P=$ 0.008 ; Figure 4E). Although translation of uORFs may activate the nonsense-mediated mRNA decay pathway [25-27], we did not observe a difference in mRNA half-life [28] between transcripts with or without evidence of active uORF translation (data not shown). Collectively, these results point towards translational repression and temporal regulation in $P$. falciparum by uORFs.

\section{Stop codon readthrough}

Similar to the 5' UTR, we observed higher average gene coverage in the 3' UTR region in the polysome- associated mRNA as compared to steady-state mRNA (Figure 4F). While a bias towards the 3' end of transcripts could be introduced by library preparation, the use of both oligo-dT and random hexamer primers during cDNA preparation should have minimized this effect. Furthermore, as this differential pattern was observed in polysomal mRNA but not in steady-state mRNA, it is likely to be biologically relevant. Since higher coverage may be indicative of translational activity, we studied the coding potential of the 3' UTR regions. In particular, we searched for the presence of in-frame ORFs that could be translated as a result of stop codon readthrough. Numerous stop codon readthrough gene candidates have been identified in other 
eukaryotes, some of which have been experimentally verified [29-34]. In addition, multiple double-readthrough gene candidates have been detected in Drosophila and other metazoa [32], indicating that this might be a common event in eukaryotic genomes. In P. falciparum, we identified 133 genes with a substantial ORF ( $>195$ nucleotides) directly downstream of the stop codon. In addition, we found another 85 genes with large downstream ORFs that had a second stop codon within the first 10 codons downstream of the annotated stop codon. The average 3' UTR coverage for these stop codon readthrough candidates was slightly increased as compared to genes with an ORF smaller than 75 nucleotides (Figure 4G), suggesting that ribosome binding and thus translation of the 3' UTR may indeed occur for these genes.

To validate our finding, we studied one of the doublereadthrough candidates in more detail. PF3D7_1345500, a ubiquitin conjugating enzyme, encodes an annotated gene product of 278 amino acids, including a 28 amino acid signal peptide that is cleaved off after translocation of the protein to the apicoplast [35]. A double-stop codon readthrough event would result in a protein that is 142 amino acids longer (Figure S4A in Additional file 2). Importantly, our polysome sequencing data confirmed that this potential second ORF was part of the full-length transcript and was highly covered by sequence reads (Figure S4B in Additional file 2). Enrichment of the 3' UTR in polysomal samples was validated by RT-PCR on an independent biological replicate (Figure S4C in Additional file 2). For this gene, three protein bands were observed by western blot analysis using a specific antibody, of which the lowest molecular weight band corresponded to the expected protein size of $33 \mathrm{kDa}$ [35]. Interestingly, the highest band exactly matches the size of a potential double-readthrough product $(51 \mathrm{kDa})$, while the middle band of approximately $48 \mathrm{kDa}$ may represent a ubiquitinylated form of the processed protein, although this remains to be experimentally verified. Taken together, these observations suggest that stop codon readthrough occurs in P. falciparum and that the currently annotated proteome is incomplete, although this will need to be verified by mass spectrometry and ribosome-footprinting experiments.

\section{Alternative splice variants}

A genome-wide search for sequence reads that did not match currently annotated splice variants resulted in the discovery of 148 novel introns and alternative splice variants in 125 genes (Table S4 in Additional file 3). Furthermore, we determined that a large fraction of introns (25\%) contained five or more mapped reads. A total of 67 highly expressed introns from 60 genes are reported in Table S5 in Additional file 4. Many of these alternative transcripts were exclusively found in steady-state
mRNA or polysomal mRNA, indicative of a specialized role for these transcripts in parasite biology. For example, PF3D7_0103200 contains an intron that is spliced out in a large proportion of transcripts detected in steady-state mRNA at $36 \mathrm{~h}$, while removal of this intron is not detected for transcripts associated with polysomes at the same time point (Figure 5A). For PF3D7_0601200, which encodes an MC-2TM protein located in the Maurer's cleft, we observed the annotated intron in steadystate mRNA at the $18 \mathrm{~h}$ time point, while the intron in polysomal mRNA started 289 nucleotides upstream of the regular donor site in the $5^{\prime}$ UTR (Figure 5B). For both genes, these observations were validated by RT-PCR using mRNA from independent biological replicates (Figure 5C).

To further study alternative splicing events, we focused on gene PF3D7_0807700, for which we observed reads mapping to intronic regions as well as reads that mapped to a truncated second exon (Figure 5D). We cloned and sequenced a cDNA fragment from total steady-state RNA corresponding to the region covering exon 2 to exon 5 of gene Pf3D7_0807700. Only one transcript out of 12 clones was identical to the currently known exon model (Figure 5E). The remaining 11 clones consisted of three different alternative transcripts, all of which contained the fourth intron, in some cases in combination with a retained third intron and/or a truncated second exon. These alternative transcripts all contained a premature stop codon, and could thus produce truncated versions of the full-length gene, or be subject to nonsense-mediated mRNA decay.

\section{Polysome-associated intronic transcripts from var genes}

The var gene family consists of approximately 60 genes each coding for a different variant of the adhesion protein Plasmodium falciparum erythrocyte membrane protein 1 (PfEMP1), which is expressed on the surface of the infected erythrocyte. PfEMP1 allows the parasite to adhere to the microvasculature, thus preventing clearance by the spleen, and causing severe disease symptoms associated with cerebral and placental malaria. In addition, the process of antigenic variation, or var gene switching, prolongs parasite survival and mediates immune escape. Although each parasite transcribes multiple (possibly all) var genes early in its erythrocytic cycle, only one PfEMP1 variant is eventually translated while the remaining variants are silenced [36]. Multiple control mechanisms are likely to be involved in this process of mutually exclusive expression, including upstream and intronic regulatory elements, localization of non-expressed var genes in nuclear repressive centers [37-39] and gene silencing by repressive histone marks $[40,41]$. In addition, two long non-coding RNAs were shown to be transcribed from the intronic regions and to be associated with chromatin [42], which is likely to 


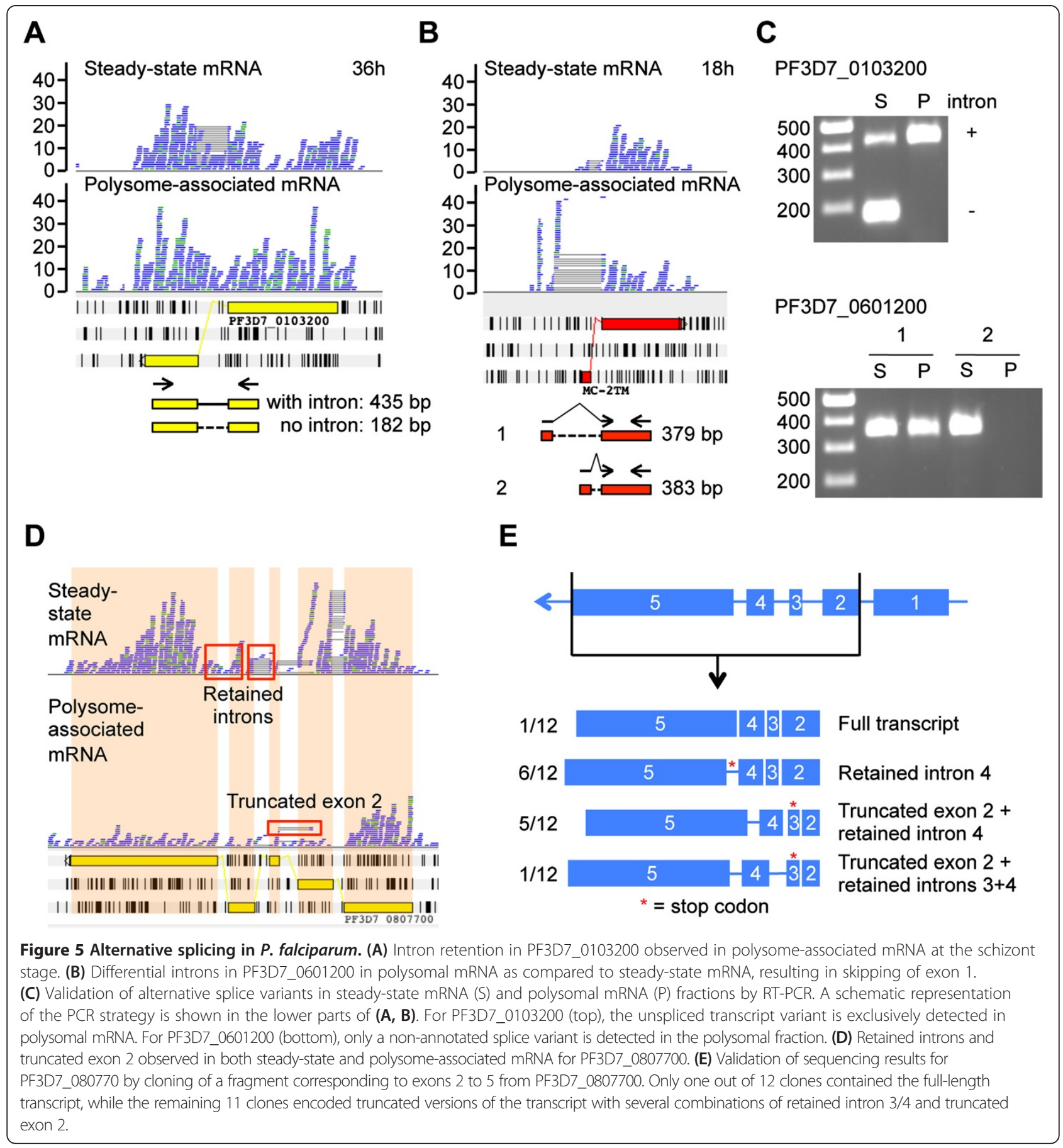

also contribute to the selective expression of var genes. However, these mechanisms are still incompletely understood and a better understanding of var gene expression would greatly facilitate novel prevention or intervention strategies for the symptomatic stage of $P$. falciparum infection.

In line with previous reports [36], we observed that all var genes produced transcripts at the $0 \mathrm{~h}$ time point within a range of two orders of magnitude (29 to 2,862 read counts per CDS), but that these transcripts were not polysome-associated. Instead, we nearly exclusively observed coverage of var introns at the $0 \mathrm{~h}$ time point in polysomal mRNA, with an average read count of 161 per intron (Figure 6). Since we used a parasite population with mixed var gene expression, we were unable to determine if this pattern was different for the var gene that would ultimately be translated by the parasite. Although the expression levels for var genes in steady- 


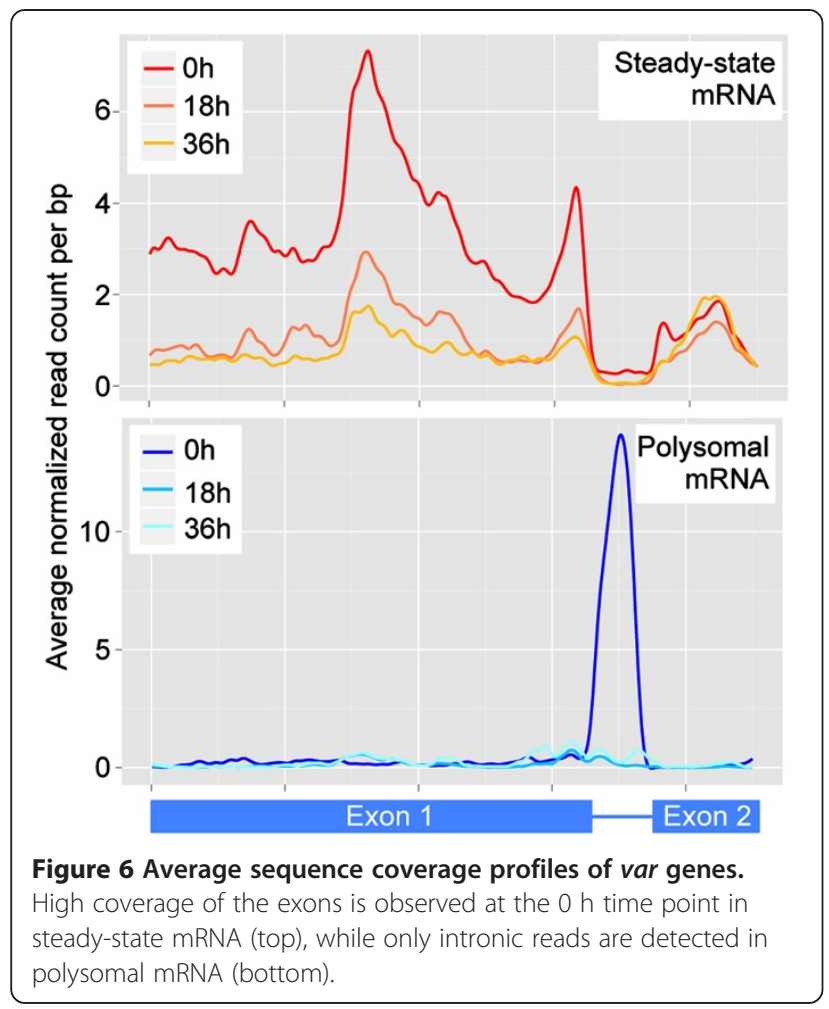

state mRNA did not directly correlate with the levels of var intron read counts in polysomal mRNA, the three var variants with the lowest exon coverage $(<50$ reads per gene) also showed very low intron coverage $(\leq 12$ reads per intron). Transcripts encoded by the var intronic region have previously been defined as noncoding RNAs. However, an investigation of the coding potential of the var introns revealed that both the sense and the antisense intronic sequence contained considerable potential ORFs with average longest ORF lengths of 205 and 155 nucleotides, respectively. Interestingly, the three genes with the lowest exon and intron read counts also contained the shortest potential ORF in the sense intronic sequence. Collectively, these data indicated that control of antigenic variation and translational repression of transcribed var genes also occur at the translational level.

\section{Discussion}

In this study, we aimed to gain a better understanding of mechanisms that control gene expression at the translational level during the asexual cell cycle of $P$. falciparum by comparing next-generation sequencing data from steady-state mRNA and polysome-associated mRNA. We determined that more than $50 \%$ of genes expressed during the asexual cycle of the malaria parasite exhibit some form of translational control, ranging from a partial shift in translation levels as compared to transcriptional activity, to a delay in translation of 18 hours or more. The results from this genome-wide analysis confirm and extend previous findings from smaller scale comparisons of the $P$. falciparum transcriptome and proteome $[9,10]$. In comparison with other eukaryotic genomes, $P$. falciparum encodes relatively few transcriptionassociated proteins, while it was found to be enriched for proteins involved in chromatin remodeling, translation rates and mRNA stability [6].

Based on these observations, we propose a gene expression model for $P$. falciparum in which the absence of a tight regulatory network for transcription is compensated by post-transcriptional and translational control mechanisms, resulting in a just-in-time translation of proteins. In particular, the parasite seems to have developed a mechanism of delayed translation for proteins that are needed early in the cell cycle, many of which play important roles in erythrocyte remodeling and metabolism. By retaining these transcripts until after reinvasion, the parasite can quickly translate proteins that are critical for its establishment inside the erythrocyte, before it starts a new round of massive transcription and replication. Translational repression by temporary storage of two transcripts in ribonucleoprotein particles has previously been described for the gametocyte stage [12]. The presence of the DDX-6 class RNA helicase DOZI is essential for the formation of these complexes. This protein was recently shown to be present in granular bodies in the cytoplasm of asexual parasites [43], and it is tempting to speculate that DOZI may also be involved in storage of transcripts during the asexual cell cycle.

The wealth of information obtained from RNA-Seq experiments allowed us to subsequently perform an in-depth comparison between these two mRNA subpopulations. We identified major differences in mRNA landscape between steady-state mRNA and polysomal mRNA, which provide important clues for potential regulatory mechanisms. Compared to other eukaryotes, $P$. falciparum genes contain relatively long 5' UTRs [44]. Recently, the 5' UTR of the household gene phosphoglucomutase-2 (PGM2; PFD0660w) was shown to play an important role in translation efficiency [45]. In addition, the length and sequence context of the uORF of $P$. falciparum var gene variant var2csa was demonstrated to influence the balance between translational repression and translation initiation at the main coding sequence after uORF translation [46]. In line with knowledge from other well-studied eukaryotic organisms $[20,22,23,47]$, uORFs in the $5^{\prime}$ mRNA leaders of $P$. falciparum transcripts are likely to be important regulatory elements that control the level and timing of translation of the main coding sequence. The translation of uORFs by itself does not necessarily influence translation of downstream coding sequences, since the ribosome can continue scanning the mRNA and re-initiate translation at a downstream AUG [20,48,49]. However, the 
association we observed between uORF translation, translational delay and uORF length suggests that the main inhibitory mechanism of uORFs in P. falciparum entails the prevention of ribosomes from reaching the main ORF, possibly by activation of the nonsense-mediated decay pathway [25-27]. Alternatively, many uORFs in the high A/T-biased $P$. falciparum genome contain poly-A tracts that encode lysine repeats, which may significantly slow down the translating ribosome [50]. Furthermore, it is known that uORFs can code for functional peptides that can even exert translational control by themselves [51]. Future studies will have to elucidate the exact nature of these uORFs and their impact on translation.

Another interesting feature of translation that had not been previously described in P. falciparum is stop codon readthrough. A recent in-depth study in Drosophila classified about $2 \%$ of all genes as stop codon readthrough candidates [32], indicating that this may be a relatively common event in eukaryotes. Although further studies will need to validate the occurrence of stop codon readthrough at similar levels in $P$. falciparum, this process could possibly explain the unexpected large size of at least one protein. Phylogenetic analysis of evolutionary constraints on 3' UTRs and computational methods for the identification of coding regions could shed more light on this mechanism, although currently available tools may have to be adapted for the highly A/T-rich genome of $P$. falciparum. In this respect, it is also interesting to mention that relatively long $3^{\prime}$ UTRs, as frequently observed in $P$. falciparum transcripts, may also harbor binding sites for long non-coding RNAs (lncRNAs) that could influence translation efficiency, similar to what is observed in mammalian neuronal tissues [52].

We detected novel alternative splice variants in the asexual cell cycle of $P$. falciparum, thereby expanding the number of alternative splice variants that are currently annotated or have previously been described in multiple independent RNA-Seq datasets from the same stages $[4,18,53]$. In addition, we also observed that a large proportion of genes contained sequence reads that mapped to introns. Since the majority of introns were completely devoid of reads, this is unlikely to be caused by DNA contamination of our mRNA samples. Intron coverage can be the result of intron retention in the transcript, or the transcription of overlapping RNAs, either in a sense or anti-sense direction, as is known to occur in P. falciparum [53,54]. Alternatively, introns are known to contain many non-protein-coding RNAs (ncRNAs) [55], that can be independent transcripts or be derived from the pre-mRNA. While a number of small nucleolar RNAs (snoRNAs), RNAs of unknown function (RUFs) and other ncRNAs encoded by intronic regions have previously been described for the $P$. falciparum genome [56,57], the widespread detection of intronic coverage is suggestive of a much larger number of regulatory RNAs encoded by introns. In addition, the preferential association of some intronic transcripts with polysomal fractions may point to functions in translational regulation. The apparent role of intron-encoded transcripts in translational repression of the var genes demonstrates the potent regulatory function of such RNAs, although the exact mechanism of control remains to be determined. The lack of coverage in the exons suggests that the intronic transcript involved in translational repression is distinct from the two var intronic ncRNAs that have previously been described and that either partially overlapped exon 1 or completely overlapped exon 2 [42]. Instead, it may suggest that the intron itself is retained and functional after splicing. Given the purity of our polysome fractions $(<2.0 \%$ protein contamination), it is unlikely that intronic transcripts were obtained by co-purification of other proteinRNA complexes. Furthermore, even though ribosomes are known to be sticky complexes, the high yield of intronic transcripts in polysomal fractions for virtually all var gene variants at the ring stage suggests that this is not the result of mere non-specific adherence, but of specific targeting of intronic var transcripts to ribosomes. A better understanding of the role of intronic transcripts or intron-encoded peptides in translational repression of the var genes would contribute to strategies for disrupting the mutually exclusive var gene expression, thus preventing escape of the parasite from adaptive immune responses.

\section{Conclusions}

Collectively, this study has shown that the regulation of translation in P. falciparum is a multi-faceted process of high complexity. Several control mechanisms that have previously been described in higher eukaryotes are also likely to be active in the malaria parasite, including translational repression by upstream ORFs, widespread transcription of non-coding transcripts, and alternative splicing events. This study clearly demonstrates that steady-state mRNA levels are often not predictive for translational activity and that translated transcript variants may differ from the general mRNA population, as recently also shown for human cells [58], indicating that the compartment of actively translated transcripts should not be overlooked. A detailed understanding of the regulatory network that determines gene expression in the different stages of the $P$. falciparum life cycle will not only increase our knowledge of parasite biology, but may ultimately result in the identification of novel antimalarial drug targets.

\section{Materials and methods Parasite culture}

The P. falciparum strain 3D7 was cultured in human $\mathrm{O}^{+}$ erythrocytes at $5 \%$ hematocrit as previously described [59]. Cultures were synchronized twice at ring stage with 
5\% D-sorbitol treatments performed 8 hours apart [60]. Cultures (8\% parasitemia in 5\% hematocrit in a total volume of $25 \mathrm{ml}$ ) were harvested 48 hours after the first sorbitol treatment (ring stage), and then 18 hours (trophozoite stage) and 36 hours thereafter (schizont stage).

\section{Total RNA extraction}

Total RNA was isolated from parasites by adding 5 volumes of pre-warmed Trizol LS Reagent (Life Technologies, Carlsbad, CA, USA) to pelleted infected erythrocytes, followed by a 5 minute incubation at $37^{\circ} \mathrm{C}$. RNA isolation was then continued according to the manufacturer's instructions.

\section{Polysome-associated RNA isolation}

Polysomes were isolated from P. falciparum according to a recently published protocol [16]. Briefly, cycloheximide was added to parasite-infected red blood cell cultures to a final concentration of $200 \mu \mathrm{M}$, followed by a 10 minute incubation at $37^{\circ} \mathrm{C}$. Erythrocytes were then pelleted (4 minutes at $660 \mathrm{x} \mathrm{g}$ ) and washed twice in phosphate-buffered saline containing $200 \mu \mathrm{M}$ cycloheximide. After the last wash, pellets were kept on ice and were subsequently lysed by adding 2.2 volumes of lysis buffer (1\% (v/v) Igepal CA-360 and 0.5\% (w/v) sodium deoxycholate in polysome buffer $(400 \mathrm{mM}$ potassium acetate, $25 \mathrm{mM}$ potassium HEPES $\mathrm{pH}$ 7.2, $15 \mathrm{mM}$ magnesium acetate, $200 \mu \mathrm{M}$ cycloheximide, $1 \mathrm{mM}$ dithiothreitol (DTT), and $1 \mathrm{mM}$ 4-(2-aminoethyl)benzenesulfonyl fluoride $\mathrm{HCl}(\mathrm{AEBSF}))$ ). After a 10 minute incubation on ice, lysates were centrifuged for 10 minutes at $20,000 \mathrm{x}$ g at $4^{\circ} \mathrm{C}$. The clarified lysates were then loaded on top of a sucrose cushion (1 M sucrose in polysome buffer) to concentrate the ribosomes. For large cultures volumes, $20 \mathrm{ml}$ lysate was loaded on top of $6 \mathrm{ml}$ of sucrose cushion in $26 \mathrm{ml}$ polycarbonate ultracentrifuge tubes and then centrifuged for $3 \mathrm{~h}$ at 50,000 rpm at $4^{\circ} \mathrm{C}$ in a Type $70 \mathrm{Ti}$ rotor (Beckman Coulter, Brea, CA, USA). For small culture volumes, $4 \mathrm{ml}$ lysate was loaded atop $1.25 \mathrm{ml}$ of sucrose cushion in $5 \mathrm{ml}$ polyallomer ultracentrifuge tubes and then centrifuged for 123 minutes at $50,000 \mathrm{rpm}$ at $4^{\circ} \mathrm{C}$ in an SW $55 \mathrm{Ti}$ rotor (Beckman Coulter). Ribosome pellets were resuspended in polysome buffer, incubated for at least 30 minutes at $4^{\circ} \mathrm{C}$ to allow complete ribosome resuspension and centrifuged for 10 minutes at $12,000 \mathrm{x} \mathrm{g}$ at $4^{\circ} \mathrm{C}$. The ribosome suspension was layered on top of a $4.5 \mathrm{ml}$ continuous linear 15 to $60 \%$ sucrose $(\mathrm{w} / \mathrm{v})$ gradient in polysome buffer and centrifuged for $1.5 \mathrm{~h}$ at 50,000 rpm at $4^{\circ} \mathrm{C}$ in an SW $55 \mathrm{Ti}$ rotor. Fractions of $400 \mu \mathrm{l}$ were collected using an UA-5 UV detector and model 185 gradient fractionator (ISCO, Lincoln, NE, USA). Polysome fractions were digested with $200 \mu \mathrm{g}$ Proteinase K (New England Biolabs (NEB), Ipswich, MA, USA) for $1 \mathrm{~h}$ at $37^{\circ} \mathrm{C}$. RNA was extracted with acid-phenol:chloroform:isoamylalcohol, pH 4.5 (Life Technologies), extracted twice with chloroform and then precipitated using isopropanol.

\section{Multidimensional protein identification technology}

Pooled polysome fractions from a mixed-stage P. falciparum culture were analyzed for protein content using MudPIT. Proteins were precipitated with $20 \%$ trichloroacetic acid (TCA). The resulting pellet was washed once with 10\% TCA and twice with cold acetone. TCAprecipitated protein pellet (approximately $50 \mu \mathrm{g}$ ) was solubilized in Tris- $\mathrm{HCl} \mathrm{pH} 8.5$ and $8 \mathrm{M}$ Urea. TCEP (Tris(2-Carboxylethyl)-Phosphine Hydrochloride; Thermo Fisher Scientific, Rockford, IL, USA) and CAM (chloroacetamide; Sigma-Aldrich, St. Louis, MO, USA) were added to a final concentration of $5 \mathrm{mM}$ and $10 \mathrm{mM}$, respectively. The protein suspension was digested overnight at $37^{\circ} \mathrm{C}$ using Endoproteinase Lys-C at 1:50 w/w (Roche, Basel, Switzerland). The sample was brought to a final concentration of $2 \mathrm{M}$ urea and $2 \mathrm{mM} \mathrm{CaCl}_{2}$ before performing a second overnight digestion at $37^{\circ} \mathrm{C}$ using Trypsin (Promega, Madison, WI, USA) at 1:100 w/w. Formic acid (5\% final) was added to stop the reactions. The sample was loaded on split-triple-phase fused-silica microcapillary column [61] and placed in-line with LQT Velos Pro mass spectrometer (Thermo Fisher Scientific), coupled with quaternary Agilent 1260 series high-performance liquid chromatography. A fully automated 10-step chromatography run (for a total of 20 hours) was carried out, as described in [62]. Each full mass spectrometry (MS) scan (400 to $1,600 \mathrm{~m} / \mathrm{z})$ was followed by 10 datadependent tandem MS (MS/MS) scans. The number of the micro scans was set to 1 for both MS and MS/MS. The dynamic exclusion settings used were as follows: repeat count 2; repeat duration $30 \mathrm{~s}$; exclusion list size 500 and exclusion duration $90 \mathrm{~s}$, while the minimum signal threshold was set to 500. The MS/MS dataset was searched using SEQUEST [63] against a database of 72,358 sequences, consisting of 5,487 P. falciparum non-redundant proteins (downloaded from PlasmoDB on 12 July 2012), 30,536 H. sapiens non-redundant proteins (downloaded from NCBI on 27 August 2012), 177 usual contaminants (such as human keratins, IgGs, and proteolytic enzymes), and, to estimate false discovery rates, 36,179 randomized amino acid sequences derived from each non-redundant protein entry. To account for alkylation by CAM, $57 \mathrm{Da}$ were added statically to cysteine residues. To account for the oxidation of methionine residues to methionine sulfoxide (that can occur as an artifact during sample processing), $16 \mathrm{Da}$ were added as a differential modification to methionine residue. Peptide/spectrum matches were sorted, selected using DTASelect/CONTRAST [64]. Proteins had to be detected by one peptide with two independent spectra, 
leading to false discovery rates at the protein and spectral levels of $2.89 \%$ and $0.26 \%$, respectively. To estimate relative protein levels and to account for peptides shared between proteins, Normalized Spectral Abundance Factors (dNSAFs) were calculated for each detected protein, as described in [65]. Lists of all proteins that were detected in our sample and individual peptide/spectral counts are provided in Table S1 in Additional file 1. The mass spectrometry proteomics data have been deposited to the ProteomeXchange Consortium [66] via the PRIDE partner repository [67] with the dataset identifier PXD000553. The MS .RAW files, .ms2 files created by RawDistiller, the .sqt files generated by SEQUEST, and the DTASelect output files for this analysis are also available to download from The Stowers Institute Original Data Repository [68].

\section{mRNA isolation and CDNA preparation}

To remove potential DNA contamination, RNA samples were treated twice with $1 \mathrm{U}$ DNase I (Life Technologies) per $10 \mu \mathrm{g}$ of RNA for 30 minutes at $37^{\circ} \mathrm{C}$, followed by inactivation of the DNase I enzyme. The absence of DNA was confirmed by performing a 40-cycle PCR on P. falciparum gene PF05_139450 using 200 to 500 ng total RNA as input. Messenger RNA was then purified from total RNA samples using the GenElute mRNA Miniprep kit (Sigma-Aldrich) according to the manufacturer's instructions.

The preparation of double-stranded cDNA from steady-state mRNA and polysome-associated mRNA samples was adapted from a previously published method [69]. Up to $500 \mathrm{ng}$ of mRNA was diluted 1:5 in RNA storage solution (Life Technologies) and was fragmented by a 50 minute incubation at $98^{\circ} \mathrm{C}$. The fragmented mRNA was added to $3 \mu \mathrm{g}$ of random hexamers (Integrated DNA Technologies, Coralville, IA, USA), $1 \mu \mathrm{g}$ of anchored oligo $(\mathrm{dT})_{20}$ (Integrated DNA Technologies) and $1 \mu \mathrm{l} 10 \mathrm{mM}$ dNTP mix (Life Technologies) in a total volume of $10 \mu \mathrm{l}$. The mixture was incubated for 10 minutes at $70^{\circ} \mathrm{C}$ and chilled on ice for 5 minutes. Next, a mix of $2 \mu \mathrm{l}$ 10X RT buffer, $4 \mu \mathrm{l} 20 \mathrm{mM} \mathrm{MgCl}$, $2 \mu \mathrm{l} 0.1 \mathrm{M}$ DTT, $1 \mu \mathrm{l} 40 \mathrm{U} / \mu \mathrm{l}$ RNaseOUT and $1 \mu \mathrm{l}$ $200 \mathrm{U} / \mu \mathrm{l}$ SuperScript III Reverse Transcriptase (all from Life Technologies) was added. First-strand cDNA was synthesized by incubating the sample for 10 minutes at $25^{\circ} \mathrm{C}, 50$ minutes at $50^{\circ} \mathrm{C}$, and finally 5 minutes at $85^{\circ} \mathrm{C}$. The first-strand cDNA was then purified using Agencourt AMPure XP beads (Beckman Coulter) and eluted in $47 \mu \mathrm{l}$ of nuclease-free water. Second-strand cDNA was prepared by adding $2 \mu \mathrm{l} 5 \mathrm{X}$ first-strand buffer (Life Technologies), $1 \mu$ l 0.1 M DTT (Life Technologies), $15 \mu \mathrm{l}$ second-strand buffer (Life Technologies), $4 \mu \mathrm{l}$ $10 \mathrm{mM}$ dNTP mix (Life Technologies), $4 \mu \mathrm{l} 10 \mathrm{U} / \mu \mathrm{l}$ E. coli DNA Polymerase (NEB), $1 \mu \mathrm{l} 10 \mathrm{U} / \mu \mathrm{l}$ E. coli
DNA ligase (NEB), and $1 \mu \mathrm{l} 2 \mathrm{U} / \mu \mathrm{l}$ E. coli RNase $\mathrm{H}$ (Life Technologies) and incubating the mixture for $2 \mathrm{~h}$ at $16^{\circ} \mathrm{C}$. Finally, double-stranded cDNA was purified using Agencourt AMPure XP beads.

\section{Library preparations and sequencing}

Libraries from steady-state mRNA samples were prepared using the Encore Multiplexing System (NuGEN, San Carlos, CA, USA) according to the manufacturer's instructions, with the following modifications for the high AT content of the P. falciparum genome: the libraries were amplified for a total of 15 PCR cycles $(5$ cycles of $15 \mathrm{~s}$ at $98^{\circ} \mathrm{C}, 30 \mathrm{~s}$ at $55^{\circ} \mathrm{C}, 30 \mathrm{~s}$ at $62^{\circ} \mathrm{C}$ followed by 10 cycles of $15 \mathrm{~s}$ at $98^{\circ} \mathrm{C}, 30 \mathrm{~s}$ at $63^{\circ} \mathrm{C}, 30 \mathrm{~s}$ at $\left.72^{\circ} \mathrm{C}\right)$ using KAPA HiFi HotStart Ready Mix (Kapa Biosystems, Woburn, MA, USA). Libraries from polysome-associated mRNA samples were prepared using the NEBNext ChIP-Seq Library Preparation kit (NEB) according to the manufacturer's instructions, with the exception of the use of the KAPA HiFi Hotstart Ready Mix for the amplification of the libraries. Depending on the amount of input DNA, libraries were amplified for a total of 11 to 15 PCR cycles ( 3 to 5 cycles of $15 \mathrm{~s}$ at $98^{\circ} \mathrm{C}, 30 \mathrm{~s}$ at $55^{\circ} \mathrm{C}$, $30 \mathrm{~s}$ at $62^{\circ} \mathrm{C}$ followed by 8 to 10 cycles of $15 \mathrm{~s}$ at $98^{\circ} \mathrm{C}$, $30 \mathrm{~s}$ at $63^{\circ} \mathrm{C}, 30 \mathrm{~s}$ at $72^{\circ} \mathrm{C}$ ). Libraries of steady-state mRNA samples and of polysomal mRNA samples were multiplexed and were sequenced on two separate lanes with a HiSeq 2000 (Illumina, San Diego, CA, USA), generating 50 bp paired-end sequence reads. By multiplexing all libraries of one sample type into one lane, we attempted to minimize differences in cluster generation and other sequencing artifacts between samples of the same type. The selection of library preparation kits for the construction of sequence libraries was solely based on availability. In our hands, we have not noticed any differences or biases between library preparation kits used in this study. RNA-Seq and polysome-Seq sequence reads are available from the Short Read Archive under accession number SRP021890.

\section{Sequence mapping}

The first five bases and the last base were systematically removed from the sequence reads using FastQ Trimmer, part of the FASTX-Toolkit [70]. Contaminating adaptor reads were removed using Scythe [71]. Reads were then trimmed for bases with a quality score below 30, and reads containing any Ns as well as reads shorter than 18 bases were discarded using Sickle [72]. Subsequently, the trimmed sequence reads were mapped to $P$. falciparum genome v9.0 (downloaded from PlasmoDB [73]) using tophat v2.0.3 [74], allowing a maximum of one mismatch per read segment and no insertions or deletions. We removed all reads that were non-uniquely mapped (using Samtools v0.1.18 [75]), not properly paired 
(Samtools), PCR duplicates (using Picard Tools v1.78 [76]) or mapped to either ribosomal DNA or to DNA encoding transfer RNA (using Bedtools v2.17.0 [77]). The final number of working reads for each library is listed in Table 1.

\section{Data normalization}

For each gene, the number of reads mapping to its exons was calculated (Bedtools). Exon read counts per gene were normalized for GC content and gene length using the open-source Bioconductor R package EDASeq [78]. In our experience, expression values of short genes with low read counts ( $<5$ reads per gene) are highly inflated using this package. To minimize overestimating expression levels of such genes, genes that did not reach five mapped reads at any time point in both steady-state mRNA and polysomal mRNA were removed from the datasets before applying the normalization algorithm. For genes with annotated alternative splice variants, only the first variant (annotated with .1 in its gene name) was included. Non-protein coding transcripts (annotated as 'transcript', not 'mRNA' in PlasmoDB-9.0_Pfalciparum3D7.gff) and small nuclear RNAs (snRNAs) were also excluded. Next, to normalize the exon read counts to the mRNA levels per parasite, a scaling factor was calculated for each stage based on the mRNA yield per flask of P. falciparum-infected culture (Table 1). For each stage, the total number of working reads was divided by the total number of working reads from the smallest library for that sample type (that is, steady-state mRNA or polysomal mRNA), and was subsequently multiplied by the ratio between the mRNA yield per flask for the stage of the smallest library and the mRNA yield per flask for that particular stage. The exon counts per gene were then divided by this scaling factor. The final normalized abundance values were expressed as counts per kilobase of exon model. Finally, for both steady-state mRNA and polysomal mRNA datasets, genes that were not expressed were excluded from further analysis. Nonexpressed genes were defined as having $<15 \%$ of the median counts per kilobase of exon model (18.9 counts for the steady-state mRNA dataset and 4.0 counts for the polysomal mRNA dataset) at all stages. Because of differences in library sizes, RPKM cutoff values differed for each library, but were at least 0.7. An overview of exon read counts before, during, and after the different normalization steps is provided in Additional file 5.

\section{Gene clustering and gene ontology analysis}

Cluster analysis was performed for genes that were differentially expressed during the cell cycle, defined as a more than two-fold change in exon read counts at any time during the cell cycle, in both steady-state mRNA and polysomal mRNA datasets. For both datasets, genes were subsequently clustered based on scaled expression levels (z-score) using the k-means clustering algorithm with a maximum of 1,000 iterations in R v2.14.2. Several independent clustering runs were performed with increasing numbers of clusters. Determination of the optimal number of clusters was guided by the percentage of variance that was captured by the clusters. We selected the smallest number of clusters that captured more than 90\% of the variance (expressed as within group sum of squares) and for which an increase in clusters did not yield a cluster with a novel expression profile (as determined by eye). For both steady-state mRNA and polysomal mRNA, more than $90 \%$ of variance could be explained by five or more clusters. Adding a sixth cluster to the polysomal mRNA dataset resulted in a novel cluster (B.6; genes expressed at ring and schizont stage) that was not observed with five or less clusters. The optimal number of clusters was therefore determined to be five clusters for the steady-state mRNA dataset and six clusters for polysomal mRNA dataset. GO analysis was performed for each cluster using the Bioconductor R package goseq [79]. Enriched GO terms were identified using a false discovery rate cutoff of 0.05 .

\section{UTR coverage}

Only genes that are located at least $1,000 \mathrm{bp}$ from neighboring genes were included in analyses of $5^{\prime}$ UTR and 3' UTR coverage. The extent of 5' UTR coverage was calculated as the ratio between the number of reads that map to the first $500 \mathrm{bp}$ upstream of the start codon and the number of reads that mapped to the coding sequence (expressed per $500 \mathrm{bp}$ to correct for gene size). The numbers of reads mapping to the different gene regions are provided in Additional file 5.

\section{Coverage plots}

Coverage plots were prepared by extracting the normalized read counts for the region of interest for all genes included in the analysis, scaling the read counts for each gene (z-score) and subsequently calculating the average value for each nucleotide position. Coverage profiles were smoothed in $\mathrm{R}$ using the function smooth.spline with a smoothing parameter of 0.35 , and were subsequently plotted using bioconductor $\mathrm{R}$ package ggplot 2 . For the var genes, normalized read counts for exon 1, intron, and exon 2 were extracted separately and were divided into bins of approximately equal length (that is, 650 bins for exon 1, 100 bins for intron and 150 bins for exon 2). The average coverage of each bin was calculated and used for subsequent scaling and averaging across the total length of all var genes.

\section{Semi-quantitative reverse transcription PCR}

Reverse transcription was performed for unfragmented steady-state or polysome-associated mRNA using random 
hexamers and oligo-dT(20) as described above. For directional reverse transcription, three separate cDNA synthesis reactions were performed using 2 pmole of either a forward or a reverse gene-specific primer, or no primer as a control for self-priming (primers are listed in Table S6 in Additional file 2). Subsequently, semi-quantitative PCRs were performed using the KAPA HiFi Hotstart Ready Mix supplemented with $10 \mathrm{ng}$ of cDNA and 10 pmole of both forward and reverse primers. DNA was amplified by incubation for 5 minutes at $95^{\circ} \mathrm{C}$, followed by 35 cycles of $30 \mathrm{~s}$ at $98^{\circ} \mathrm{C}, 30 \mathrm{~s}$ at $55^{\circ} \mathrm{C}, 30 \mathrm{~s}$ at $62^{\circ} \mathrm{C}$. Samples of $5 \mu \mathrm{lob}-$ tained after cycles 25,30 and 35 were analyzed by agarose gel electrophoresis. For each primer set, a separate amplification reaction using genomic DNA was performed to control for differences in PCR efficiency.

\section{Northern blotting analysis}

Samples analyzed by northern blot were obtained from independent biological experiments as replicates of sequenced samples. Each RNA sample was loaded in two concentrations, containing $2 \mu \mathrm{g}$ (left lane) and $8 \mu \mathrm{g}$ (right lane) of total RNA, respectively. RNA was separated on a $1.2 \%$ formaldehyde-agarose gel for 3.5 hours at $40 \mathrm{~V}$. After rinsing the gel twice for 15 minutes in 20X SSC, RNA was transferred for 2.5 hours to Hybond $\mathrm{N}+$ membrane (GE Healthcare, Waukesha, WI, USA) using Northern Max Transfer Buffer (Life Technologies), according to the manufacturer's instructions. After transfer, RNA was cross-linked to the membrane by UV exposure. RNA detection was performed using the DIG Northern Starter Kit (Roche) according to the manufacturer's instructions with minor modifications for the highly A/T-rich P. falciparum genome. Briefly, PCR products were amplified in advance using primers that included the sequence of the SP6 polymerase promoter (primers are listed in Table S6 in Additional file 2). DIGlabeled RNA probes were prepared by incubation of the PCR product with SP6 polymerase in the presence of DIG-labeled nucleotides for 2 hours at $42^{\circ} \mathrm{C}$. RNA probes were diluted in ethanol, titrated, stored at $-20^{\circ} \mathrm{C}$ and boiled for 5 minutes just before use. RNA blots were blocked for 30 minutes at 50 to $55^{\circ} \mathrm{C}$ in pre-warmed $1 \mathrm{X}$ DIG Easy Hyb solution and were then incubated $\mathrm{O} / \mathrm{N}$ at 50 to $55^{\circ} \mathrm{C}$ in pre-warmed 1X DIG Easy Hyb buffer supplemented with $100 \mathrm{ng} / \mathrm{ml}$ of DIG-labeled probe. Blots were washed twice for 5 minutes in 2X SCC, $0.1 \%$ SDS at room temperature under constant agitation, followed by two 15 minute washes in pre-warmed $0.1 \mathrm{X}$ SSC, $0.1 \%$ SDS at 50 to $55^{\circ} \mathrm{C}$ under constant agitation. After these stringency washes, blots were rinsed in washing buffer, incubated for 30 minutes in blocking solution, incubated for 30 minutes in antibody solution, followed by two 15 minute washes in washing buffer and a 2 minute equilibration in detection buffer. Blots were developed using CDP-Star solution, and were exposed to X-ray film for approximately 25 minutes.

\section{Analysis of coding potential}

The coding potential of a region in the genome ( $5^{\prime}$ UTR, intron, or 3' UTR) was determined by scanning for ORFs in all three translation frames. Out of all possible ORFs, only the longest was recorded. For var gene introns, this analysis was repeated for the antisense strand.

\section{Detection of unannotated introns and alternative splice variants}

The intron/exon boundaries of all intron-spanning reads (defined by samtools CIGAR string $\mathrm{dMdNdM}$ where $\mathrm{d}$ is one or more digits) were compared to annotated intron/ exon boundaries and were selected for further inspection when one or both intron boundaries were different from current PlasmoDB (version 9.0) annotations. All introns with one unannotated intron/exon boundary supported by at least 5 sequence reads and all novel introns (both intron/exon boundaries unannotated) with at least 10 supporting reads were manually verified in a genome browser and were compared to previously reported alternative splice variants $[4,18,53]$.

\section{Analysis of intronic reads}

Analysis of intronic reads was performed for genes without annotated alternative splice variants. For each intron, we determined the number of intron-spanning reads and the number of sequence reads for which at least $90 \%$ of the read length mapped to the intron itself. The ratio of intronic versus intron-spanning reads was then calculated by dividing the number of intronic reads per 100 nucleotides of intron length by the number of intron-spanning reads (one read was added to this number for calculation purposes). To reduce the chance that reads mapping to an intron were derived from an overlapping neighboring gene, only genes that are located at least $750 \mathrm{bp}$ from their nearest annotated neighboring genes were analyzed. Introns with at least 10 reads per 100 nucleotides and at least twice the number of intronic reads versus intron-spanning reads were reported. The numbers of intronic and intronspanning reads are provided in Additional file 5.

\section{Additional files}

\footnotetext{
Additional file 1: MudPIT analysis of polysome fractions.

Additional file 2: Figure S1. Validation of sequencing data. Figure S2. Distribution of normalized read counts per gene for the ring, trophozoite and schizont stages of $P$. falciparum. Figure S3. Characterization of genes with high 5' UTR coverage in polysome-associated mRNA. Figure S4. Stop codon readthrough candidate in $P$. falciparum. Table S2. Enriched gene ontology terms for steady-state mRNA expression clusters. Table S3. Enriched gene ontology terms for polysomal mRNA expression clusters. Table S6. Sequences of primers used for PCR and northern blot analyses.
} 


\section{Additional file 3: Novel introns and alternative splice variants detected in this study.}

Additional file 4: Highly expressed introns.

Additional file 5: Raw and normalized exon counts for all genes, as well as numbers of reads mapped to the regions $500 \mathrm{bp}$ upstream and 500 bp downstream of each gene. For genes containing introns, the number of reads mapped to each intron and the number of intron-spanning reads are also provided.

\section{Abbreviations}

bp: Base pair; CAM: Chloroacetamide; CDS: Coding sequence; GO: Gene ontology; MS: Mass spectrometry; MS/MS: Tandem mass spectrometry; MudPIT: Multidimensional protein identification technology; ncRNA: Nonprotein-coding RNA; NEB: New England Biolabs; ORF: Open reading frame; TCA: Trichloroacetic acid; uORF: Upstream open reading frame; UTR: Untranslated region.

\section{Competing interests}

The authors declare that they have no competing interests.

\section{Authors' contributions}

EMB generated sequence data, analyzed the data and wrote the manuscript. DWDC and NP generated sequence data and edited the manuscript. MH performed cloning experiments and edited the manuscript. AS and LF analyzed protein samples by mass-spectrometry (MudPIT). JP maintained parasite cultures and edited the manuscript. KGLR designed the study, supervised the project and wrote the manuscript. All authors read and approved the final manuscript.

\section{Acknowledgements}

We thank Piyada Juntawong, Maureen Hummel, and Julia Bailey-Serres for their help in polysome profiling experiments, and John Weger, Rebecca Sun, and Glenn Hicks (Institute for Integrative Genome Biology, University of California Riverside) for their assistance in the library preparation and sequencing process. We thank Julie Bailey-Serres, Frances Sladek and Fedor Karginov for critical reading of the manuscript. The 3D7 parasite strain was obtained through the MR4 (MRA-102) deposited by DJ Carucci. This study was financially supported by the Human Frontier Science Program (grant LT000507/2011-L to EMB) and the National Institutes of Health (grant R01 Al85077-01A1 to KLR).

\section{Author details}

'Department of Cell Biology and Neuroscience, University of California Riverside, 900 University Ave, Riverside, CA 92521, USA. ${ }^{2}$ Current address: INRA Centre de Bordeaux Aquitaine, 33883 Villenave d'Ornon, Cedex, France. ${ }^{3}$ Stowers Institute for Medical Research, Kansas City, MO 64110, USA. ${ }^{4}$ Institute for Integrative Genome Biology, Center for Disease Vector Research, Department of Cell Biology and Neuroscience, University of California Riverside, 900 University Avenue, Riverside, CA 92521, USA.

Received: 5 September 2013 Accepted: 22 November 2013 Published: 22 November 2013

\section{References}

1. WHO: World Malaria Report. 2012. [http://www.who.int/malaria/publications/ world_malaria_report_2012/en/]

2. Bozdech Z, Llinas M, Pulliam BL, Wong ED, Zhu J, DeRisi JL: The transcriptome of the intraerythrocytic developmental cycle of Plasmodium falciparum. PLOS Biol 2003, 1:E5.

3. Le Roch KG, Zhou Y, Blair PL, Grainger M, Moch JK, Haynes JD, De La Vega P, Holder AA, Batalov S, Carucci DJ, Winzeler EA: Discovery of gene function by expression profiling of the malaria parasite life cycle. Science 2003, 301:1503-1508.

4. Otto TD, Wilinski D, Assefa S, Keane TM, Sarry LR, Bohme U, Lemieux J, Barrell B, Pain A, Berriman M, Newbold C, Llinás M: New insights into the blood-stage transcriptome of Plasmodium falciparum using RNA-Seq. Mol Microbiol 2010, 76:12-24.

5. Balaji S, Babu MM, lyer LM, Aravind L: Discovery of the principal specific transcription factors of Apicomplexa and their implication for the evolution of the AP2-integrase DNA binding domains. Nucleic Acids Res 2005, 33:3994-4006.

6. Coulson RM, Hall N, Ouzounis CA: Comparative genomics of transcriptional control in the human malaria parasite Plasmodium falciparum. Genome Res 2004, 14:1548-1554

7. Ponts N, Harris EY, Lonardi S, Le Roch KG: Nucleosome occupancy at transcription start sites in the human malaria parasite: a hard-wired evolution of virulence? Infect Genet Evol 2011, 11:716-724.

8. Ponts N, Harris EY, Prudhomme J, Wick I, Eckhardt-Ludka C, Hicks GR, Hardiman G, Lonardi S, Le Roch KG: Nucleosome landscape and control of transcription in the human malaria parasite. Genome Res 2010, 20:228-238.

9. Foth BJ, Zhang N, Mok S, Preiser PR, Bozdech Z: Quantitative protein expression profiling reveals extensive post-transcriptional regulation and post-translational modifications in schizont-stage malaria parasites. Genome Biol 2008, 9:R177.

10. Le Roch KG, Johnson JR, Florens L, Zhou Y, Santrosyan A, Grainger M, Yan SF, Williamson KC, Holder AA, Carucci DJ, Yates JR 3rd, Winzeler EA: Global analysis of transcript and protein levels across the Plasmodium falciparum life cycle. Genome Res 2004, 14:2308-2318.

11. Schwanhausser B, Busse D, Li N, Dittmar G, Schuchhardt J, Wolf J, Chen W, Selbach M: Global quantification of mammalian gene expression control. Nature 2011, 473:337-342.

12. Mair GR, Braks JA, Garver LS, Wiegant JC, Hall N, Dirks RW, Khan SM, Dimopoulos G, Janse CJ, Waters AP: Regulation of sexual development of Plasmodium by translational repression. Science 2006, 313:667-669.

13. Hall N, Karras M, Raine JD, Carlton JM, Kooij TW, Berriman M, Florens L, Janssen CS, Pain A, Christophides GK, James K, Rutherford K, Harris B, Harris D, Churcher C, Quail MA, Ormond D, Doggett J, Trueman HE, Mendoza J, Bidwell SL, Rajandream MA, Carucci DJ, Yates JR 3rd, Kafatos FC, Janse CJ, Barrell B, Turner CM, Waters AP, Sinden RE: A comprehensive survey of the Plasmodium life cycle by genomic, transcriptomic, and proteomic analyses. Science 2005, 307:82-86.

14. Zhang M, Fennell C, Ranford-Cartwright L, Sakthivel R, Gueirard P, Meister S, Caspi A, Doerig C, Nussenzweig RS, Tuteja R, Sullivan WJ Jr, Roos DS, Fontoura BM, Ménard R, Winzeler EA, Nussenzweig V: The Plasmodium eukaryotic initiation factor-2alpha kinase IK2 controls the latency of sporozoites in the mosquito salivary glands. J Exp Med 2010, 207:1465-1474.

15. Aravind $L$, lyer $L M$, Wellems $T E$, Miller $L H$ : Plasmodium biology: genomic gleanings. Cell 2003, 115:771-785

16. Lacsina JR, LaMonte G, Nicchitta CV, Chi JT: Polysome profiling of the malaria parasite Plasmodium falciparum. Mol Biochem Parasitol 2011, 179:42-46.

17. Ponts N, Saraf A, Chung DW, Harris A, Prudhomme J, Washburn MP, Florens L, Le Roch KG: Unraveling the ubiquitome of the human malaria parasite. J Biol Chem 2011, 286:40320-40330.

18. Sorber K, Dimon MT, DeRisi JL: RNA-Seq analysis of splicing in Plasmodium falciparum uncovers new splice junctions, alternative splicing and splicing of antisense transcripts. Nucleic Acids Res 2011, 39:3820-3835.

19. Wang Z, Gerstein M, Snyder M: RNA-Seq: a revolutionary tool for transcriptomics. Nat Rev Genet 2009, 10:57-63.

20. Ingolia NT, Lareau LF, Weissman JS: Ribosome profiling of mouse embryonic stem cells reveals the complexity and dynamics of mammalian proteomes. Cell 2011, 147:789-802.

21. Franklin TJ, Snow GA: Inhibitors of protein biosynthesis. In Biochemistry and Molecular Biology of Antimicrobial Drug Action. Volume 6. New York: Springer; 2005. 104.

22. Calvo SE, Pagliarini DJ, Mootha VK: Upstream open reading frames cause widespread reduction of protein expression and are polymorphic among humans. Proc Natl Acad Sci U S A 2009, 106:7507-7512.

23. Kozak M: Structural features in eukaryotic mRNAs that modulate the initiation of translation. J Biol Chem 1991, 266:19867-19870.

24. Rajkowitsch L, Vilela C, Berthelot K, Ramirez CV, McCarthy JE: Reinitiation and recycling are distinct processes occurring downstream of translation termination in yeast. $J$ Mol Biol 2004, 335:71-85.

25. Gaba A, Jacobson A, Sachs MS: Ribosome occupancy of the yeast CPA upstream open reading frame termination codon modulates nonsensemediated mRNA decay. Mol Cell 2005, 20:449-460.

26. Nyiko T, Sonkoly B, Merai Z, Benkovics AH, Silhavy D: Plant upstream ORFs can trigger nonsense-mediated mRNA decay in a size-dependent manner. Plant Mol Biol 2009, 71:367-378. 
27. Arribere JA, Gilbert $W$ : Roles for transcript leaders in translation and mRNA decay revealed by Transcript Leader Sequencing. Genome Res 2013, 23:977-987.

28. Shock JL, Fischer KF, DeRisi JL: Whole-genome analysis of mRNA decay in Plasmodium falciparum reveals a global lengthening of mRNA half-life during the intra-erythrocytic development cycle. Genome Biol 2007, 8:R134.

29. Bonetti B, Fu L, Moon J, Bedwell DM: The efficiency of translation termination is determined by a synergistic interplay between upstream and downstream sequences in Saccharomyces cerevisiae. J Mol Biol 1995, 251:334-345.

30. Cassan M, Rousset JP: UAG readthrough in mammalian cells: effect of upstream and downstream stop codon contexts reveal different signals. BMC Mol Biol 2001, 2:3.

31. Firth $A E$, Wills NM, Gesteland RF, Atkins JF: Stimulation of stop codon readthrough: frequent presence of an extended 3' RNA structural element. Nucleic Acids Res 2011, 39:6679-6691

32. Jungreis I, Lin MF, Spokony R, Chan CS, Negre N, Victorsen A, White KP, Kellis M: Evidence of abundant stop codon readthrough in Drosophila and other metazoa. Genome Res 2011, 21:2096-2113.

33. Williams I, Richardson J, Starkey A, Stansfield I: Genome-wide prediction of stop codon readthrough during translation in the yeast Saccharomyces cerevisiae. Nucleic Acids Res 2004, 32:6605-6616.

34. Berry MJ, Banu L, Larsen PR: Type I iodothyronine deiodinase is a selenocysteine-containing enzyme. Nature 1991, 349:438-440.

35. Agrawal S, Chung DW, Ponts N, van Dooren GG, Prudhomme J, Brooks CF, Rodrigues EM, Tan JC, Ferdig MT, Striepen B, Le Roch KG: An apicoplast localized ubiquitylation system is required for the import of nuclear-encoded plastid proteins. PLOS Pathog 2013, 9:e1003426.

36. Chen Q, Fernandez V, Sundstrom A, Schlichtherle M, Datta S, Hagblom P, Wahlgren M: Developmental selection of var gene expression in Plasmodium falciparum. Nature 1998, 394:392-395.

37. Duraisingh MT, Voss TS, Marty AJ, Duffy MF, Good RT, Thompson JK, FreitasJunior LH, Scherf A, Crabb BS, Cowman AF: Heterochromatin silencing and locus repositioning linked to regulation of virulence genes in Plasmodium falciparum. Cell 2005, 121:13-24.

38. Dzikowski R, Li F, Amulic B, Eisberg A, Frank M, Patel S, Wellems TE, Deitsch $\mathrm{KW}$ : Mechanisms underlying mutually exclusive expression of virulence genes by malaria parasites. EMBO Rep 2007, 8:959-965.

39. Lopez-Rubio JJ, Mancio-Silva L, Scherf A: Genome-wide analysis of heterochromatin associates clonally variant gene regulation with perinuclear repressive centers in malaria parasites. Cell Host Microbe 2009, 5:179-190.

40. Freitas-Junior LH, Hernandez-Rivas R, Ralph SA, Montiel-Condado D, Ruvalcaba-Salazar OK, Rojas-Meza AP, Mancio-Silva L, Leal-Silvestre RJ, Gontijo AM, Shorte S, Scherf A: Telomeric heterochromatin propagation and histone acetylation control mutually exclusive expression of antigenic variation genes in malaria parasites. Cell 2005, 121:25-36.

41. Lopez-Rubio JJ, Gontijo AM, Nunes MC, Issar N, Hernandez Rivas R, Scherf A: $5^{\prime}$ flanking region of var genes nucleate histone modification patterns linked to phenotypic inheritance of virulence traits in malaria parasites. Mol Microbiol 2007, 66:1296-1305.

42. Epp C, Li F, Howitt CA, Chookajorn T, Deitsch KW: Chromatin associated sense and antisense noncoding RNAs are transcribed from the var gene family of virulence genes of the malaria parasite Plasmodium falciparum. RNA 2009, 15:116-127

43. Tarique M, Ahmad M, Ansari A, Tuteja R: Plasmodium falciparum DOZI, an RNA helicase interacts with elF4E. Gene 2013, 522:46-59.

44. Russell K, Hasenkamp S, Emes R, Horrocks P: Analysis of the spatial and temporal arrangement of transcripts over intergenic regions in the human malarial parasite Plasmodium falciparum. BMC Genomics 2013, 14:267.

45. Hasenkamp S, Russell K, Ullah I, Horrocks P: Functional analysis of the $5^{\prime}$ untranslated region of the phosphoglutamase 2 transcript in Plasmodium falciparum. Acta tropica 2013, 127:69-74.

46. Bancells $C$, Deitsch KW: A molecular switch in the efficiency of translation reinitiation controls expression of var2csa, a gene implicated in pregnancy associated malaria. Mol Microbiol 2013, 90:472-488.

47. Oliveira CC, MCCarthy JE: The relationship between eukaryotic translation and mRNA stability, A short upstream open reading frame strongly inhibits translational initiation and greatly accelerates mRNA degradation in the yeast Saccharomyces cerevisiae. J Biol Chem 1995, 270:8936-8943
48. Cao J, Geballe AP: Translational inhibition by a human cytomegalovirus upstream open reading frame despite inefficient utilization of its AUG codon. J Virol 1995, 69:1030-1036.

49. Mize GJ, Ruan H, Low JJ, Morris DR: The inhibitory upstream open reading frame from mammalian S-adenosylmethionine decarboxylase mRNA has a strict sequence specificity in critical positions. J Biol Chem 1998, 273:32500-32505.

50. Charneski CA, Hurst LD: Positively charged residues are the major determinants of ribosomal velocity. PLOS Biol 2013, 11:e1001508.

51. Rahmani F, Hummel M, Schuurmans J, Wiese-Klinkenberg A, Smeekens S, Hanson J: Sucrose control of translation mediated by an upstream open reading frame-encoded peptide. Plant Physio/ 2009, 150:1356-1367.

52. Miura P, Shenker S, Andreu-Agullo C, Westholm JO, Lai EC: Widespread and extensive lengthening of 3' UTRs in the mammalian brain. Genome Res 2013, 23:12-25.

53. Lopez-Barragan MJ, Lemieux J, Quinones M, Williamson KC, Molina-Cruz A Cui K, Barillas-Mury C, Zhao K, Su XZ: Directional gene expression and antisense transcripts in sexual and asexual stages of Plasmodium falciparum. BMC Genomics 2011, 12:587.

54. Gunasekera AM, Patankar S, Schug J, Eisen G, Kissinger J, Roos D, Wirth DF: Widespread distribution of antisense transcripts in the Plasmodium falciparum genome. Mol Biochem Parasitol 2004, 136:35-42.

55. Rearick D, Prakash A, McSweeny A, Shepard SS, Fedorova L, Fedorov A: Critical association of ncRNA with introns. Nucleic Acids Res 2011, 39:2357-2366.

56. Chakrabarti K, Pearson M, Grate L, Sterne-Weiler T, Deans J, Donohue JP, Ares M Jr: Structural RNAs of known and unknown function identified in malaria parasites by comparative genomics and RNA analysis. RNA 2007 13:1923-1939.

57. Mourier T, Carret C, Kyes S, Christodoulou Z, Gardner PP, Jeffares DC, Pinches R, Barrell B, Berriman M, Griffiths-Jones S, Ivans A, Newbold C, Pain $A$ : Genome-wide discovery and verification of novel structured RNAs in Plasmodium falciparum. Genome Res 2008, 18:281-292.

58. Sterne-Weiler T, Martinez-Nunez RT, Howard JM, Cvitovik I, Katzman S, Tariq MA, Pourmand N, Sanford JR: Frac-seq reveals isoform-specific recruitment to polyribosomes. Genome Res 2013, 23:1615-1623.

59. Trager W, Jensen JB: Human malaria parasites in continuous culture. Science 1976, 193:673-675

60. Lambros C, Vanderberg JP: Synchronization of Plasmodium falciparum erythrocytic stages in culture. J Parasitol 1979, 65:418-420.

61. McDonald WH, Ohi R, Miyamoto DT, Mitchison TJ, Yates JR: Comparison of three directly coupled HPLC MS/MS strategies for identification of proteins from complex mixtures: single-dimension LCMS/MS, 2-phase MudPIT, and 3-phase MudPIT. Int J Mass Spectrom 2002, 251:245-251.

62. Florens L, Washburn MP: Proteomic analysis by multidimensional protein identification technology. Methods Mol Biol 2006, 328:159-175.

63. Eng JK, McCormack AL, Yates JR: An approach to correlate tandem mass spectral data of peptides with amino acid sequences in a protein database. J Am Soc Mass Spectrom 1994, 5:976-989.

64. Tabb DL, McDonald WH, Yates JR 3rd: DTASelect and Contrast: tools for assembling and comparing protein identifications from shotgun proteomics. J Proteome Res 2002, 1:21-26.

65. Zhang Y, Wen Z, Washburn MP, Florens L: Refinements to label free proteome quantitation: how to deal with peptides shared by multiple proteins. Anal Chem 2010, 82:2272-2281.

66. ProteomeXchange. [http://proteomecentral.proteomexchange.org]

67. Vizcaino JA, Cote RG, Csordas A, Dianes JA, Fabregat A, Foster JM, Griss J, Alpi E, Birim M, Contell J, O'Kelly G, Schoenegger A, Ovelleiro D, PérezRiverol Y, Reisinger F, Rios D, Wang R, Hermjakob J: The PRoteomics IDEntifications (PRIDE) database and associated tools: status in 2013. Nucleic Acids Res 2013, 41:D1063-D1069.

68. Stowers Institute Original Data Repository. [http://srdr.stowers.org/]

69. Yassour M, Pfiffner J, Levin JZ, Adiconis X, Gnirke A, Nusbaum C, Thompson DA, Friedman N, Regev A: Strand-specific RNA sequencing reveals extensive regulated long antisense transcripts that are conserved across yeast species. Genome Biol 2010, 11:R87.

70. FASTX-Toolkit. [http://hannonlab.cshl.edu/fastx_toolkit/index.html]

71. Scythe. [https://github.com/ucdavis-bioinformatics/scythe]

72. Sickle. [https://github.com/ucdavis-bioinformatics/sickle]

73. PlasmoDB. [http://plasmodb.org/plasmo/]

74. Trapnell C, Pachter L, Salzberg SL: TopHat: discovering splice junctions with RNA-Seq. Bioinformatics 2009, 25:1105-1111. 
75. Li H, Handsaker B, Wysoker A, Fennell T, Ruan J, Homer N, Marth G, Abecasis G, Durbin R: The Sequence Alignment/Map format and SAMtools. Bioinformatics 2009, 25:2078-2079.

76. Picard. [http://picard.sourceforge.net/]

77. Quinlan AR, Hall IM: BEDTools: a flexible suite of utilities for comparing genomic features. Bioinformatics 2010, 26:841-842.

78. Risso D, Schwartz K, Sherlock G, Dudoit S: GC-content normalization for RNA-Seq data. BMC Bioinforma 2011, 12:480

79. Young MD, Wakefield MJ, Smyth GK, Oshlack A: Gene ontology analysis for RNA-seq: accounting for selection bias. Genome Biol 2010, 11:R14.

doi:10.1186/gb-2013-14-11-r128

Cite this article as: Bunnik et al.: Polysome profiling reveals translational control of gene expression in the human malaria parasite Plasmodium falciparum. Genome Biology 2013 14:R128.

\section{Submit your next manuscript to BioMed Central and take full advantage of:}

- Convenient online submission

- Thorough peer review

- No space constraints or color figure charges

- Immediate publication on acceptance

- Inclusion in PubMed, CAS, Scopus and Google Scholar

- Research which is freely available for redistribution 